\title{
An optimal condition based maintenance scheduling for metal structures based on a multidisciplinary research approach
}

\author{
Jawwad Latif, Zulfiqar A Khan, Mian H Nazir \\ Bournemouth University, Department of Design \& Engineering, NanoCorr, Energy and Modelling \\ (NCEM) \\ Keith Stokes \\ University of Southampton, National Centre for Advanced Tribology at Southampton (nCATS) \\ Faculty of Engineering and the Environment, Southampton SO17 1BJ \\ Richard Smith \\ Director, The Tank Museum, Linsay Rd, Bovington, Wareham BH20 6JG
}

Corresponding author name: Zulfiqar A Khan

Corresponding author e-mail: zkhan@bournemouth.ac.uk 


\title{
An optimal condition based maintenance scheduling for metal structures based on a multidisciplinary research approach
}

\begin{abstract}
Latest research findings show that the deterioration of metal coatings results due to complex combination of material and meteorological parameters. The classical maintenance scheduling do not consider complex interface of materials and meteorological parameters to determine optimal maintenance framework. The cost of recoating can be optimised through appropriate selection of coating specifications and maintenance strategy. This research provides a multidisciplinary algorithmic approach to determine cost-effective solutions for recoating. The specifications of red oxide primer coating and structural steel substrate system are considered for simulation analysis. The results show that the appropriate selection of $10 \%$ increase in coating thickness based on coatingsubstrate system specifications resulted in 20-25\% reduction in annual patch failures which reduces 5$6 \%$ cost of recoating. Furthermore, the proposed model also simulated to compare Patch recoating and Part recoating strategy and algorithm show that the Part recoating is cost-effective as compared to Patch recoating if number of annual patch failure is greater than ' 2 ' and area of the part is ' $2 x$ 'times larger than the area of the patch. Contrary, the Patch recoating results in low cost if the part area is ' $10 \mathrm{x}$ ' times larger than patch area and number of annual patch failures are less than ' 7 '.
\end{abstract}

Keywords: Structures, Maintenance strategy, Recoating cost, Blistering, Condition based maintenance, Predictive modelling, Corrosion cost

\begin{tabular}{|c|c|}
\hline \multicolumn{2}{|c|}{ Nomenclature } \\
\hline$\overline{\mathrm{V}_{\mathrm{pk}}}$ & Partial molar volume \\
\hline $\mathrm{c}_{\mathrm{k}}^{\prime}$ & Concentration gradient \\
\hline $\mathrm{E}_{\mathrm{i}}$ & Elastic modulus of $\mathrm{i}^{\text {the }}$ coating material \\
\hline $\mathrm{h}_{\mathrm{i}}$ & Thickness of $\mathrm{i}^{\text {th }}$ layer of coating \\
\hline $\mathrm{v}_{\mathrm{i}}$ & Poisson's ratio of $\mathrm{i}^{\text {th }}$ material \\
\hline$\sigma_{\mathrm{cr}}$ & Critical stress of single layer coating \\
\hline $\mathrm{T}_{\mathrm{th}}$ & Total thickness of coating \\
\hline$\sigma_{\mathrm{T}}$ & Total unbuckled stress \\
\hline $\mathrm{n}$ & De-bonding index \\
\hline$\Gamma_{\mathrm{IC}}$ & Interface toughness \\
\hline $\mathrm{F}_{\mathrm{cr}}$ & Critical de-bonding driving force \\
\hline $\mathrm{F}$ & De-bonding driving force \\
\hline $\mathrm{M}_{\mathrm{Th}}$ & Threshold bending moment \\
\hline
\end{tabular}




\begin{tabular}{|c|c|}
\hline $\mathrm{M}_{\mathrm{ini}}$ & Initiation bending moment \\
\hline$a$ & Blister diameter \\
\hline$w$ & Blister amplitude \\
\hline$\sigma_{r}$ & Residual stress \\
\hline$E$ & Elastic modulus \\
\hline$\varepsilon$ & strain \\
\hline$\alpha$ & coefficient of thermal expansion mismatch \\
\hline$M$ & bending moment \\
\hline$\lambda$ & roughness \\
\hline$N$ & pre-buckling stress \\
\hline$F_{c}$ & future cost \\
\hline$i r$ & interest rate \\
\hline$A r_{p}$ & Patch area to be recoat \\
\hline$S p_{p}$ & Surface preparation cost \\
\hline$C_{p}$ & Patch coating cost \\
\hline$A_{e}$ & Total area of vehicle to recoat \\
\hline$S p_{e}$ & Surface preparation cost \\
\hline$C_{e}$ & Coating cost \\
\hline$A r_{c}$ & Component area to be recoat \\
\hline$S p_{c}$ & Part surface preparation cost \\
\hline$C_{c}$ & Cost of Part coating \\
\hline$t_{p}$ & Time duration for patch failure \\
\hline$t_{c}$ & Time duration for Part failure \\
\hline$T_{e}$ & Time duration for complete failure \\
\hline
\end{tabular}

\section{Introduction}

In the past decades, great attention has been given in determining the financial impact of corrosion damage and corresponding maintenance in various industrial organisations. The cost factor includes the cost of corrosion prevention techniques, inspection policies, research and development of finding optimise solutions and various other maintenance related activities. The cost of corrosion computed in recent years is equal to around $3.4 \%$ of GDP which is a direct cost. Meanwhile, the addition of indirect cost of corrosion accumulates the financial loss twice (Koch et al., 2016). The drinking water and sewer systems, motor vehicles and defence sector experiences substantial financial loss due to corrosion damages. The military applications cost around $23 \%$ of the budget due to corrosion damage and maintenance. The improvement in reliability by applying effective corrosion detection, control and prevention methods can result in around 15 to $35 \%$ in cost savings (Koch et al., 2016). 
The LMI government consulting organisation has issued several reports on the cost of corrosion for military vehicles (Hertzberg, 2016; Herzberg et al., 2006). The method used to determine the annual cost was authorised by the Corrosion Prevention and Control Integrated Team (CPCIPT). The method estimates the direct cost which includes labour and material cost along with indirect cost which includes training and research and development etc.. The primary objective of this study is to determine the sustainment annual cost of corrosion for military vehicles and identify the possible opportunities for cost reduction. Total of 520 types of ground military vehicles containing 446,000 individual parts of vehicle structure are considered to conduct the study for determination of the cost of corrosion and associated maintenance. Other cost elements include labour cost, material cost, coating, Blige cleaning, inspections, disposal, scrap and testing equipment.

The total estimation of the annual cost of corrosion for military vehicles was $\$ 2.019$ billion in 2006 report (Herzberg et al., 2006). According to the latest report published by LMI in 2016, the cost of corrosion estimated for the army equipment was $\$ 3.1$ billion which $15.5 \%$ of total maintenance expenditure of equipments (Hertzberg, 2016). The largest corrosion cost has been incurred by preventive measures such as inspections, cleaning, washing, recoating and washing. An effective recoating maintenance strategy can impact in the reduction of maintenance activities such as inspection, recoating, washing and surface treatment. The current work will provide algorithm for cost-effective recoating maintenance strategy which based on multidisciplinary parameters along with the labour, material, coating, inspection and surface preparation factors.

\subsection{Research findings at "The Tank Museum",UK}

The NCEM research group has been involved in investigation of structural integrity of large military vehicles at The Tank Museum, Bovington, UK. The large military vehicles are operating in diverse and harsh environmental conditions. The outcome of research findings resulted in development of The Vehicle Conservation Centre to provide a suitable environment for high priority structures. The experimental investigations also lead to the development of state-of-the-art prognostic models by incorporating complex parameters to predict the failure mechanism.

The corrosion reaction on metal structures has been observed for several years using sensor suite by embedding Linear Polarisation resistors, temperature and humidity sensors on military vehicles. The primary objective of the research findings at "The Tank Museum" is to provide the solutions for proactive maintenance scheduling in order to prolong the service life at optimal cost without compromising the integrity of structures. The large military vehicles are subjected to various types of structural failures and undergo scheduled recoating maintenance. The Figures $1 \mathrm{a}$ and $1 \mathrm{~b}$ illustrate the flex disc and hull Part of Valentine tank operating in controlled and uncontrolled environmental conditions for the past several years resulted in significant damage due to coating failure and corrosion phenomena. 
The scheduled recoating maintenance is carried out after the appropriate amount of time without considering cost implications. The Figures 1c and 1d illustrate the Parts has been recoated with red oxide primer and top coat. It is obvious that lots of cost implications are associated with the maintenance of complex metal structures including frequency of inspections due to uncertainty in structural failure, cost of surface preparation, cost of coating, labour cost and delay in service/production. The large military vehicles at "The Tank Museum" assembled of numerous parts/components and designed in various geometrical shapes. The deterioration phenomena on parts shown in Figures 1a and $1 \mathrm{~b}$ started from patch failure leading to Part failure. The solution is required to utilise the research findings in order to estimate the optimal recoating maintenance strategy among Patch recoat, Part recoat and Complete recoat.

\section{Before recoat}

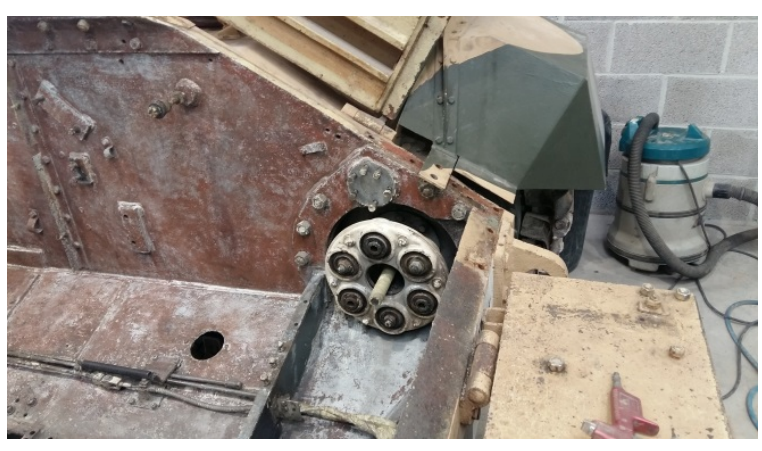

(a) Flexible Drive and Hull of Valentine Tank

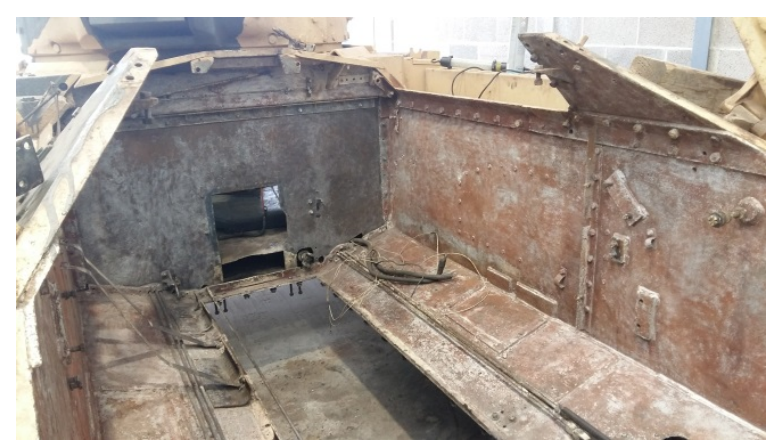

(b) Complete view of Hull of Valentine Tank

After recoat

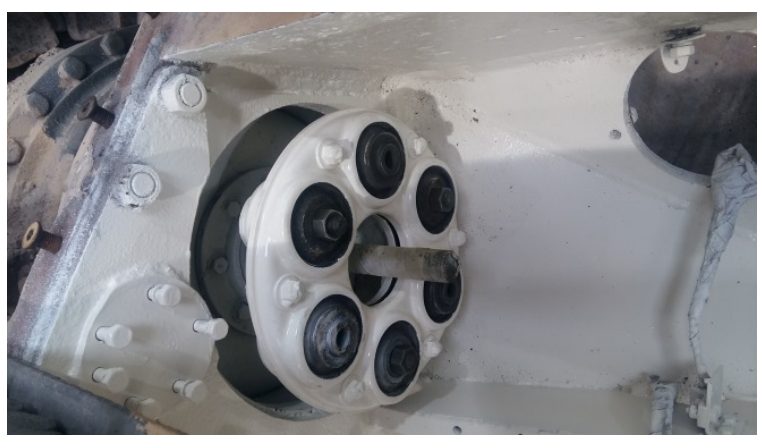

(c) Flexible Drive and Hull of Valentine Tank

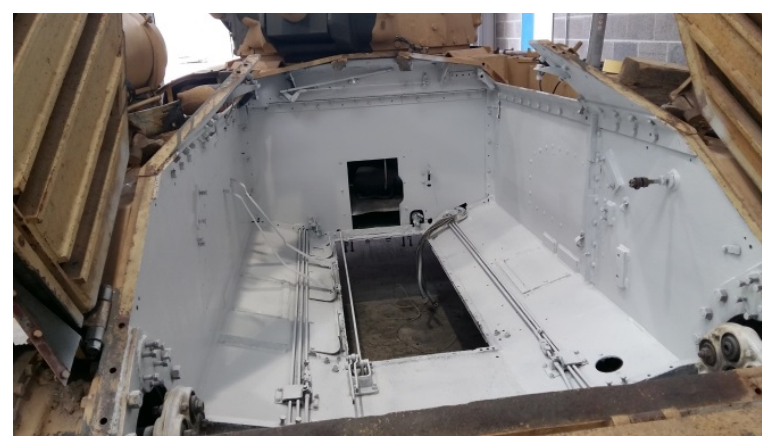

(d) Complete view of Hull of Valentine Tank

Figure 1. The Valentine Tank before and after maintenance

\subsection{Prognostic modelling of corrosion and coating failure}

The structure experiences various types of failure such as adhesion loss, abrasion, bleaching, blistering, cathodic disbonding, cracking, edge corrosion, erosion etc. The inappropriate coating application process, improper drying, mechanical loading effect combined with electrochemical processes makes it difficult to understand the coating failure phenomena. The other prognostic models related to corrosion can also be embedded in the proposed algorithmic approach to estimate the rusting and associated cost. In the past decade, the various blistering mathematical relation has been proposed to understand the initiation and propagation of blistering phenomena within the thin coating. 
The major prognostic models for coating failure in terms of cathodic blistering has been summarised in (Nazir \& Khan, 2017) . The mechanical properties were observed through experimentation and mathematical relation has been derived for blister formation as a function of blister height and pressure in relation to the elastic energy release rate (Wan \& Liao, 1999).

Later on, the elastic energy release rate was formulated as a function of coating thickness and stiffness, blister height, and pressure (Bressers, Peteves, \& Steen, 2000; Galindo, Van Veen, Evans, Schut, \& de Hosson, 2005). The mathematical relation for energy release rate as a function of coating stiffness, pressure, height and radius of height was developed in (Kappes, Frankel, \& Sridhar, 2010). The fracture mechanics concepts are combined with diffusion concept to better describe the blistering phenomena (Prawoto, 2013; Prawoto \& Dillon, 2012).

Research within NanoCorr Energy Modeling and Research group extended the multidisciplinary approach to model cathodic blistering and derived a comprehensive prognostic model to predict the formation and propagation of blister (Latif, Khan, Nazir, Stokes, \& Plummer, 2018b; Nazir, Khan, Saeed, \& Stokes, 2016a; Prawoto, 2013). The relations for energy release rate based on a multidisciplinary approach has also been derived for straight sided blisters (Khan, Latif, Hammad Nazir, \& Stokes, 2018). The algorithm based on multi-disciplinary approach was also extended to blister propagation and the speed at which blister will propagate (Latif et al., 2018b) . However, researchers have investigated the coating failure mechanism through various experimental methodologies and identified various parameters to explain complex coating failure mechanism which resulted in prognostic models but still needs more qualitative improvements in real time environmental conditions. The cathodic blistering is one of the most significant causes of coating degradation which has been considered in current work to determine optimal recoating maintenance strategy.

\subsection{Cost factor and maintenance modelling}

The maintenance professionals apply preventive and essential recoating maintenance scheduling irrespective of cost-benefit ratio. The Run-to-failure, Preventive and Predictive maintenance strategies are commonly practiced maintenance strategies in industries. The Run-to -failure maintenance strategy is applied to low priority structures but it is considered worst strategy in case of high priority structures. The Preventive maintenance involves timely scheduled maintenance which does not require expertise in inspection but it is inefficient for structures subjected to diverse operating conditions. The Predictive maintenance is condition based recoating strategy which is considered more efficient for high-value structures.

Common stochastic deterioration mathematical models including the Wiener process, Gamma Process, Inverse Gaussian process and general path modes are in practice to manage maintenance scheduling in various industrial applications (Si, Wang, Hu, \& Zhou, 2011; Ye \& Xie, 2015). The numerical model for the prediction of corrosion-induced concrete crack is formulated for time- 
efficient maintenance to prolong the service life of concrete structures (Yang, Xi, Li, \& Li, 2018). The optimisation framework has been proposed for seismic protective components used for highway bridges. The performance of seismic protective components based on engineered demand parameters is evaluated to derive repair cost ratio. The proposed methodology considers failure probabilities, the cost associated with replacement of components and damage ratio (Xie \& Zhang, 2018). The algorithm for optimal maintenance strategy for pipelines subjected to corrosion is proposed for efficient maintenance decision making (Gong \& Zhou, 2018).

The framework based on discrete Bayesian networks has been developed for cost-efficient decisions for Condition based maintenance (Nielsen \& Sørensen, 2018). An efficient maintenance framework can reduce the cost through decrease in recoating frequency, excessive inspections and other associated maintenance activities. The conventional maintenance strategy evaluation models do not include the multidisciplinary parameters of real-world scenario which drive the corrosion and coating failure phenomena.

The current work provides algorithmic solution for cost-effective recoating maintenance which is based on a multidisciplinary research approach. Three recoating maintenance strategies are considered such as Patch recoat, Part recoat and Complete recoat. The Patch recoating strategy involves removal of delaminated or rusted area from a specific patch and applying coating on the patch area. The Part recoat involves the surface preparation and recoating of the Part/component. The complete recoating involves preparation of the surface of all the defected areas and applies new coating including antirust, primers and top coat.

\section{Maintenance Strategy Evaluation Algorithm}

The basic architecture of Maintenance Strategy Evaluation Algorithm is shown in the Figure 2. It consists of various stages that include input parameters, computation of prognostic models and cost evaluation of maintenance strategies. The input parameters of algorithm contain specifications of the structure system, measurements from real-time condition monitoring system and historical maintenance database. The next stage is to apply prognostic models to predict the coating failure. Various prognostic models for coating failure and corrosion estimation based on meteorological factors and properties of coating -substrate system have been developed (Khan et al., 2018; Nazir \& Khan, 2017; Nazir, Khan, Saeed, \& Stokes, 2015; Nazir, Khan, \& Stokes, 2015c, 2015d, 2016; Nazir $\&$ Khan, 2015). These prognostic models can also be embedded in proposed algorithm to simulate the maintenance strategy for potential structural failures for specific application. The final stage performs the computation of annual cost associated with a maintenance strategy to determine the cost-effective best fit strategy.

The prognostic models developed by NCEM research group resulted through investigation of structural failures in large military vehicles are highly affected by various modes coating damage. 


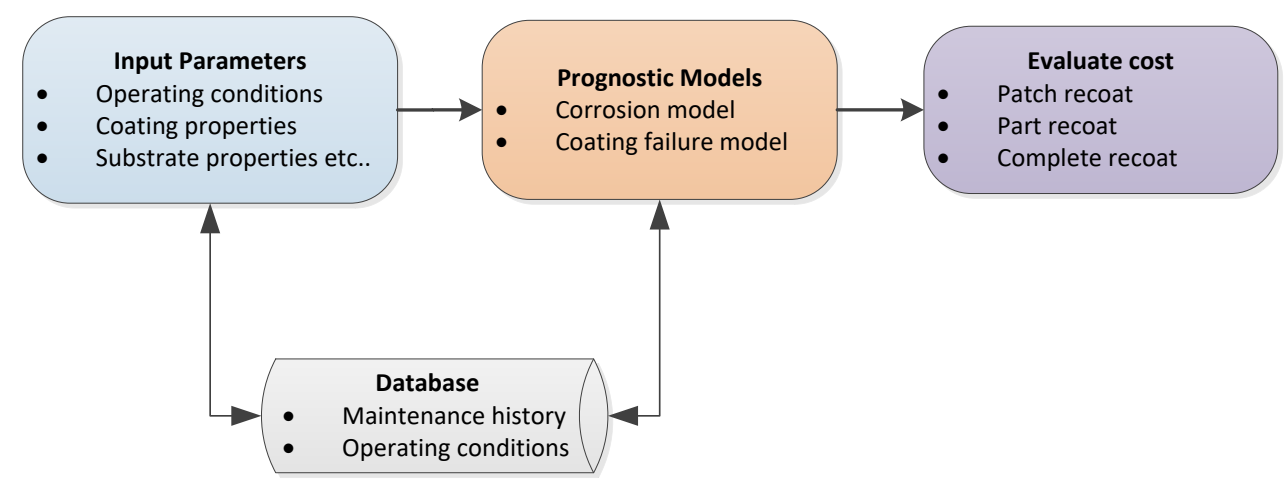

Figure 2. Basic Architecture of Maintenance Strategy Evaluation Algorithm

Therefore, the prognostic model for blistering failure is preferred for current algorithm to evaluate optimal recoating strategy for structures. The combination of complex residual and diffusion-induced stresses play vital role in development of blisters. These blisters propagate by weakening interfacial bonding between the coating and metal structure resulting in removal of coating and exposing metal structure to the surrounding environment (Chuang, Nguyen, \& Li, 1997; Irwin, 1957; Nazir, Khan, \& Stokes, 2016; Walker, 1970).

The comprehensive description of maintenance strategy evaluation algorithm is shown in the Figure 3. The prognostic model embedded in the current approach is based on latest research findings. It evaluates the performance of coating based on mechanical, chemical and environmental factors to determine the safe, critical and fail conditions of the coating. The propagation of coating failure beginning from a patch of coating failure leading to part coating failure is evaluated in case of part failure. The final stage computes the annual cost based on performance of coating resulted from prognostic model. The annual costs from different recoating strategies are compared to determine the optimal best-fit maintenance strategy. The lack of maintenance database and real-time parameters are the major challenges in evaluation of the proposed algorithm.

\subsection{Input Parameters}

According to latest research findings, the performance of coating-substrate system depends on numerous factors including the roughness of metal interface, the thickness of the coating, meteorological parameters, mechanical properties of the coating and metal structure as shown in the Figure 4.

\subsubsection{Mechanics and diffusion parameters}

The formation and propagation of blistering mechanism are driven by mechanical and diffusion parameters (Nazir, Khan, \& Stokes, 2016). The development of residuals stress and diffusion-induced stresses defines the formation and growth rate of the blistering mechanism. The residual stresses exist in the coating-substrate system that is developed during the fabrication of material and application of coating (Totten, 2002). 


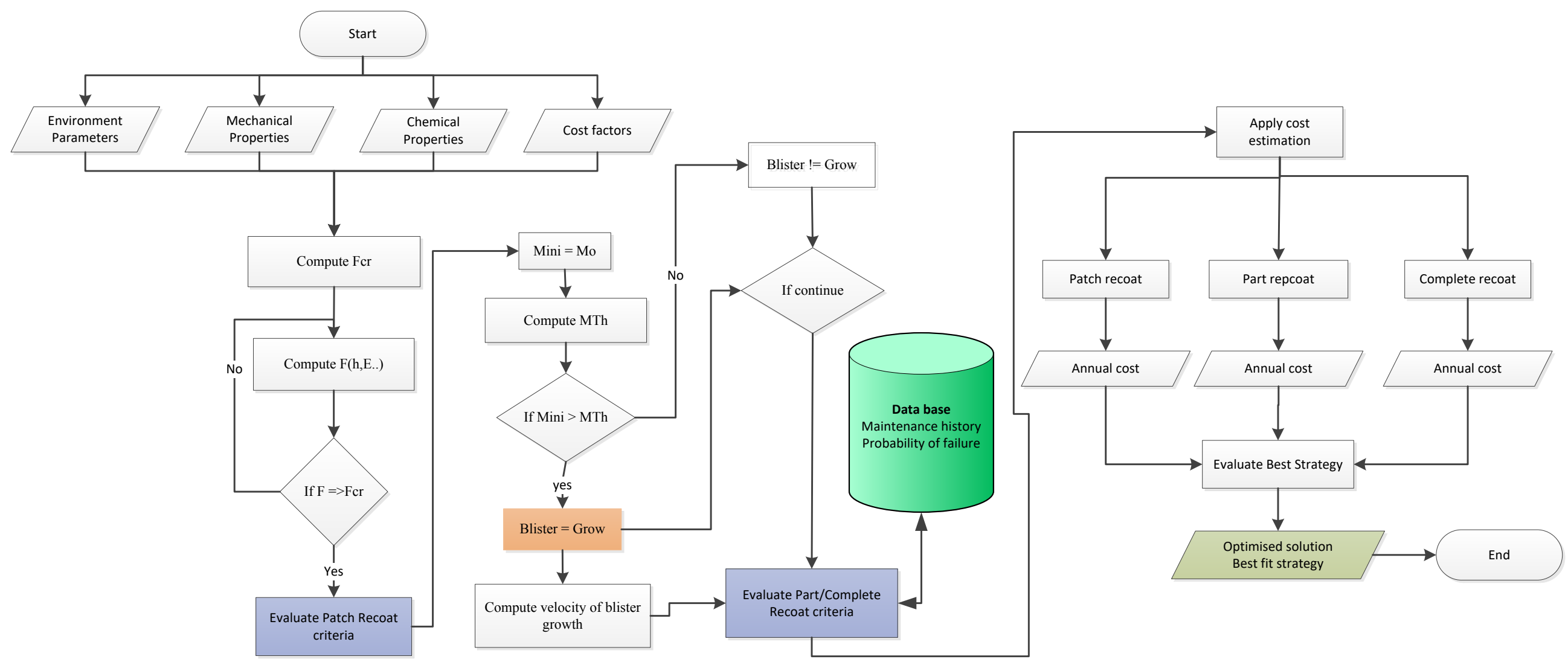

Figure 3. Recoating Maintenance Strategy Evaluation Algorithm 


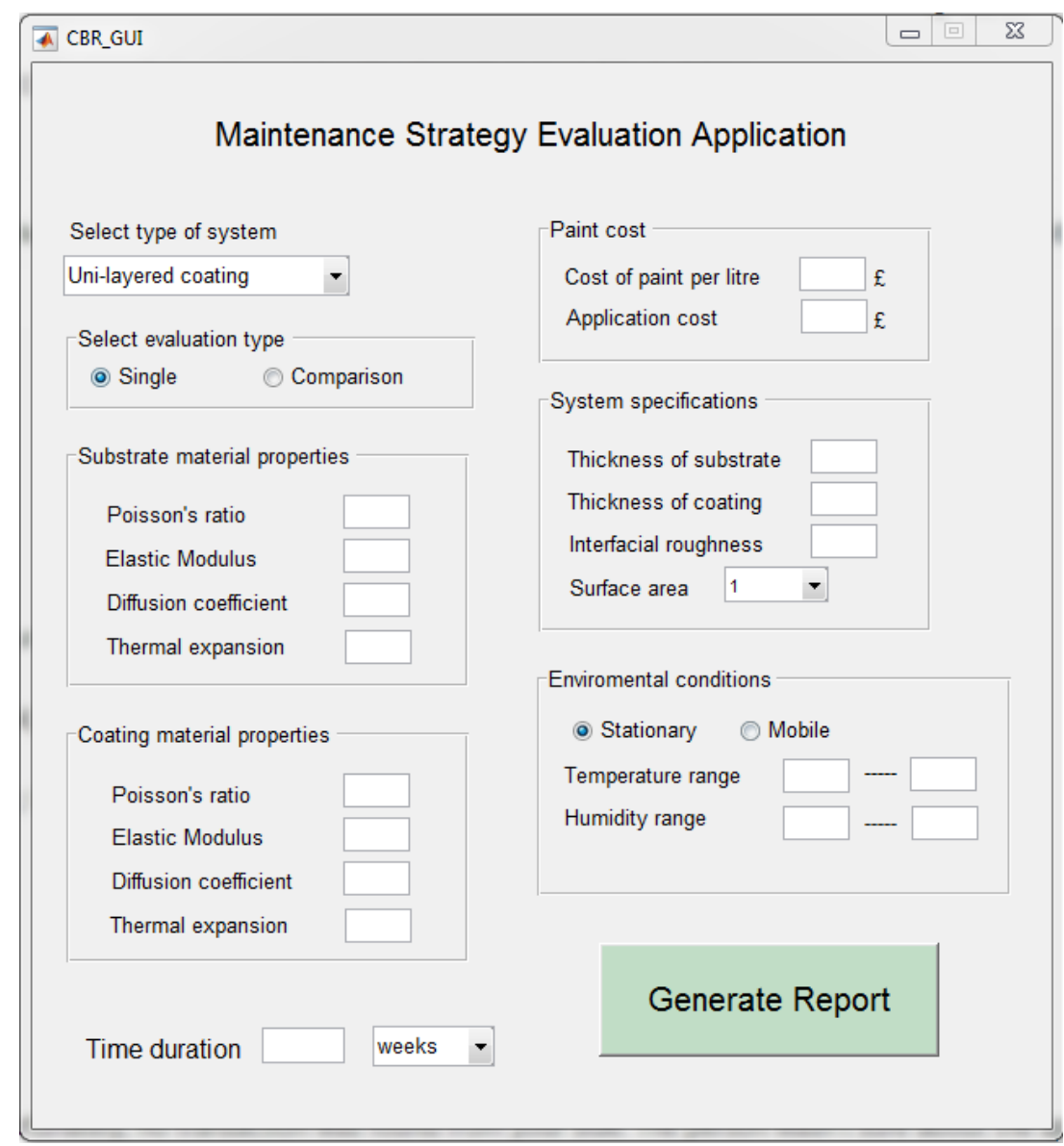

Figure 4. Input parameters

The change in temperature from fabrication temperature accounts for the tensile and compressive stresses within the coating. The tensile stresses are responsible for the opening of cracks in the coating while compressive stresses lead to blister formation (Khan et al., 2018; Nazir, Khan, Saeed, et al., 2015). The inhomogeneity conditions during diffusion process in coating produce diffusion induce stresses (Lim, Yan, Yin, \& Zhu, 2012). The relation for residual stress in the coating and substrate is given as (Hsueh, 2002):

$$
\sigma_{r}=E(\varepsilon-\alpha \Delta T)
$$

where ' $E$ ', ' $\Delta T^{\prime}$, ' $\varepsilon^{\prime}$ and ' $\alpha$ ' represents elastic modulus, temperature gradient, strain and coefficient of thermal expansion mismatch, respectively. The intrinsic thermal stresses develops due to change in temperature from application temperature, when coefficient of thermal expansion of coating and substrate are different (Hutchinson, 1996). The uncontrolled and harsh environmental conditions result in the formation of the electrochemical cell due to the reaction of salinity, water, oxygen and metal ions(Chuang, Nguyen, \& Lee, 1999). The chemical reaction drives blistering mechanism through diffusion-induced stress. The following is the expression for diffusion-induced 
stress in coating and substrate by using the analogy to thermal stress as described in (Zhang, Shyy, \& Sastry, 2007).

$$
\sigma_{d}=E\left(\varepsilon-\frac{1}{3} c^{\prime} \overline{V_{p k}}\right)
$$

where ${ }^{\prime} c^{\prime}{ }_{k}$ ' is concentration gradient of diffusing substance ' $k$ ' analogous to change in temperature and $\overline{ }^{V_{p k}}$ ' is partial molar volume of substance ' $k$ ' analogous to coefficient of thermal expansion. The residual stresses and diffusion induces stresses accounts for formation and propagation of blistering effect.

\subsubsection{Interfacial Roughness}

The adhesion between coating and substrate depends on physical parameters including interfacial roughness between coating and substrate, coating thickness and radius of impurity at the interface. According to experimental findings with variable coating-substrate interface roughness, the increase in interfacial roughness results in an increase in the adhesion as it shows maximum resistance against coating failure (Nazir \& Khan, 2015).

\subsubsection{Coating thickness}

The coating thickness is one of the major factors that affect the adhesion between the coating and substrate. The experimental analysis on steel samples with variable coating thickness has shown an increase in adhesion with respect to increasing in coating thickness (Nazir \& Khan, 2015).

\subsubsection{Cost parameters}

Several maintenance activities are involved in recoating which needs to be considered in cost evaluation besides the cost of coating applied. These cost factors breakdown into cost of surface treatment, washing, preparing equipment for application of coating, labour hours, washing, drying and other associated activities.

\subsection{Prognostic model for coating failure}

There are numerous modes of coating failures including blistering, bleeding, bridging, abrasion, bubbling, cracking and adhesion failure. While blistering is one of the common and complex coating failures that depends on the coating application process, the properties of the coating-substrate system and meteorological parameters. In current work, the formation and propagation of blistering failure have been considered to evaluate the cost-effective recoating maintenance strategy. Previously, the mathematical models for the formation and propagation of circular and straight sided blisters have been modelled and validated through experimental analysis by NCEM research group as discussed comprehensively in (Latif et al., 2018b; Nazir, Khan, et al., 2016a; Nazir, Khan, et al., 2015d; Nazir, Khan, \& Stokes, 2016). 
The proposed algorithm applies the mathematical prognostic model for the blistering mechanism. The prognostic model provides the value of de-bonding driving force which defines three states of the coating-substrate system as safe, critical and fail. For results analysis in current work, the fail condition calculated from blistering failure prognostic model is considered as patch failure. The blister could be in the form of the circular blister as well as straight-sided blisters. The relation for debonding driving force based on fracture mechanics and diffusion parameters for circular blister investigated and validated in previous research finding is given as:

$$
F=\left\{\frac{3}{2} \sum_{i=1}^{n} \frac{\left(1-v_{i}{ }^{2}\right)}{E_{i}\left(x_{i+1}-t_{p}\right)^{3}-\left(x_{i}-t_{p}\right)^{3}} M^{2}\left[1+\frac{1}{4}\left(\sqrt{n-1}^{2}\right)\right]\right\}\left\{1+\tan \left(\left(1-\frac{\Gamma_{\mathrm{IC}}}{E_{c} \lambda}\right) \tan \psi\right)^{2}\right\}^{-1}
$$

The derivation of de-bonding driving force ' $F$ ' for multilayered coating-substrate system as mentioned in above Equation (3) has been compressively discussed in (Latif et al., 2018b). In Equation (3), ' $E_{i}{ }^{\prime},{ }^{\prime} v_{i}{ }^{\prime}, \Gamma_{\mathrm{IC}},{ }^{\prime} \lambda^{\prime}$ and ' $M^{\prime}$ represents elastic modulus, poisson's ratio of $i^{\text {th }}$, interface toughness, interfacial roughness and bending moment, respectivley. The top and bottom locations of ${ }^{\prime} i{ }^{\text {th' }}$ coating are shown by ' $x_{i+1}{ }^{\prime}$ and ' $x_{i}$ '. The tan $\psi$ defines the relative mode II to mode I in fracture mechanics(Hutchinson \& Suo, 1991). The relation for tan $\psi$ can be written as following (Faulhaber, Mercer, Moon, Hutchinson, \& Evans, 2006):

$$
\tan \psi=\frac{\mathrm{K}_{2}}{\mathrm{~K}_{1}}=\frac{\sqrt{12}+\left(T_{t h} \Delta N / \Delta M\right) \tan \omega}{-\sqrt{12} \tan \omega+\left(T_{t h} \Delta N / \Delta M\right) \tan \omega}
$$

where ' $T_{t h}$ ' and ' $N$ ' represents total coating thickness and pre-buckling stress, respectively. The de-bonding index is represented by ' $\mathrm{n}$ ' which defines the safe, critical and fail condition of the coating-substrate system. If ' $\cap<1^{\prime}$ then coating-substrate system is in safe state, If ' $\cap=1^{\prime}$ then the coating-substrate system is in critical state and. If ${ }^{\prime} \cap>1^{\prime}$ then the coating-substrate system is in fail state. The de-bonding index is the ratio between resultant stress ' $\sigma_{T}{ }^{\prime}$ and critical stress ' $\sigma_{c r}$ ' (Nazir, Khan, et al., 2015c). The resultant stress is a summation of diffusion induced stress $\frac{\partial \sigma_{d_{c_{i}}}}{\partial t}$ and residual $\operatorname{stress} \frac{\partial \sigma_{r_{c_{i}}}}{\partial x}$.

$$
\begin{gathered}
\cap=\sigma_{T} / \sigma_{c r} \\
\sigma_{T}=\sigma_{d}^{\prime}+\sigma_{r}^{\prime}=\frac{\partial \sigma_{d_{c_{i}}}}{\partial t}+\frac{\partial \sigma_{r_{c_{i}}}}{\partial x}
\end{gathered}
$$




$$
\frac{\partial \sigma_{d_{c_{i}}}}{\partial t}+\frac{\partial \sigma_{r_{c_{i}}}}{\partial x}=\frac{\left(D_{k_{c_{i}}}+\frac{D_{k_{c_{i}}} E_{c_{i}} V_{p_{k_{c_{i}}}}^{2}}{9 R T} c_{k_{c_{i}}}\right) \frac{\partial^{2} c_{k_{c}}}{\partial^{2} x}+\frac{D_{k_{c_{i}}} E_{c_{i}} V_{p_{k_{c_{i}}}}^{2}}{9 R T}\left(\frac{\delta c_{k_{c_{i}}}}{\delta t}\right)^{2}}{\frac{D_{k_{c}} V_{p_{k_{c_{i}}}}^{2} \frac{\delta c_{k_{c_{i}}}}{\delta R T}}{9 R T}}
$$

The relations for resultant stress and critical stress are discussed in detail in (Nazir, Khan, et al., 2015c). When the resultant stress becomes equal to critical stress, the de-bonding index ' $\cap=1^{\prime}$ and value of de-bonding driving force is called as critical debonding driving force ' $F_{c r}$ '.

$$
F_{c r}=\left\{\frac{3}{2} \sum_{i=1}^{n} \frac{\left(1-v_{i}{ }^{2}\right)}{E_{i}\left(x_{i+1}-t_{p}\right)^{3}-\left(x_{i}-t_{p}\right)^{3}} M^{2}\right\}\left\{1+\tan \left(\left(1-\frac{\Gamma_{\mathrm{IC}}}{E_{c} \lambda}\right) \frac{1}{-\tan \omega}\right)^{2}\right\}^{-1}
$$

If the de-bonding driving force ' $F$ ' is less than critical de-bonding driving force ' $F_{c r}$ ', the coating substrate is in safe condition and when it exceeds the critical de-bonding driving force the coatingsubstrate system is considered to be in fail state as shown in Table 1.

Table 1. Conditions for patch failure

\begin{tabular}{cc}
\hline Condition & State \\
\hline $\boldsymbol{F}<\boldsymbol{F}_{c r}$ & Safe \\
$\boldsymbol{F}=\boldsymbol{F}_{c r}$ & Critical \\
$\boldsymbol{F}>\boldsymbol{F}_{c r}$ & Fail \\
\hline
\end{tabular}

The initial bending moment and threshold bending moment defines the propagation of blister mechanism (Chuang et al., 1997). The bister will grow if the initial bending moment is greater than the threshold bending moment. The relation for initial bending $\left(M_{i n i}\right)$ moment and threshold bending moment $\left(M_{T h}\right)$ can be given as:

$$
\begin{gathered}
M_{\text {ini }}=3 \frac{\sum_{i=1}^{n} E_{i} T_{t h}{ }^{3} w}{a^{2}} \\
M_{T h}=0.73 \sqrt{\sum_{i=1}^{n} \frac{E_{i}}{\left(1-v_{i}{ }^{2}\right)}} \sqrt{a \sigma_{T} T_{t h}{ }^{3}}
\end{gathered}
$$

where ' $w$ ' and ' $a$ ' represents blister amplitude and blister diameter, respectively. Although the mathematical relation for blister growth rate has been discussed in (Latif et al., 2018b) but the development of number of blisters over the Part area and a number of blisters leading to Part coating failure still needs to be coupled with de-bonding driving force. The profile for de-bonding driving force is show in Figure 5a. The de-bonding driving force approaches critical level as time increases which results in patch failure. The ' $t_{p}{ }^{\prime}$ represents the time at which patch recoating maintenance is applied. The coating failure can also lead to Part/component failure. The time at which part recoating maintenance is applied is represented by ' $t_{c}{ }^{\prime}$. The part failure depends on the geometrical shape, 
number of blisters per area and growth rate of failure propagation. The component-wise approach is required by incorporating its mechanical and geometrical characteristics for accurate estimation of corrosion damage and associated maintenance for complex structures (Cavallo, Pagani, Zappino, \& Carrera, 2018). The model for failure and propagation proposed in (Latif et al., 2018b) could be further extended for part failure through incorporating maintenance history, real time monitoring of environmental conditions and experimental investigations. The maintenance of noncritical structures can also be delayed for complete failure. The ' $T_{e}$ ' represents the time at which structure require complete recoating maintenance.

\subsection{Uniform database for maintenance history}

The proposed recoating maintenance scheduling is based on complex parameters of real-time scenario which have not been considered in conventional maintenance evaluation techniques. The current solution requires historical data to efficient feedback system to minimise error rate in predictions of failures. Therefore, a uniform database is required to maintain historical maintenance data which should include all possible multidisciplinary parameters as shown in Table 2. The multidisciplinary parameters mentioned in database require various methodologies for measurements. The methods needs be applied on various stages of recoating process. The typical recoating maintenance activities involve several stages such as surface treatment before coating, application of coating followed by drying stage and then structure is sent for normal operational activities.

The proposed historical database requires recording several parameters at each stage. The several methodologies including optical microscopy, X-ray fluorescence and Scanning electron microscopy to acquire parameters such as interfacial roughness of metal-substrate or thickness of coating have been reported in previous experimental research work of NCEM (Khan et al., 2018; Khan, Latif, Nazir, Stokes, \& Plummer, 2017; Latif, Khan, Nazir, Stokes, \& Plummer, 2018a; Nazir, Khan, \& Stokes, 2015a; Nazir \& Khan, 2017; Nazir, Khan, Saeed, et al., 2015; Nazir, Khan, et al., 2016a; Nazir, Khan, Saeed, \& Stokes, 2016b; Nazir, Khan, \& Stokes, 2015b; Nazir, Khan, et al., 2015c, 2015d; Nazir, Khan, \& Stokes, 2016; Nazir, Saeed, \& Khan, 2018; Nazir \& Khan, 2015; Nazir, Khan, \& Saeed, 2018; Nazir, Saeed, \& Khan, 2017; Saeed, Khan, Nazir, Hadfield, \& Smith, 2017; Saeed, Khan, \& Nazir, 2015; Saeed, Khan, \& Nazir, 2016). The independent steel sample with same coating and substrate specifications can be used for measurements.

Furthermore, the sensor technology along with wireless communication system can be installed on metal structure to acquire the critical parameters during its operational activities such as corrosion, temperature, humidity and stresses. The corrosion can be monitored using linear polarisation resistor sensors reported comprehensively in (Latif et al., 2018a). The strain gauge sensors can be used to monitor the development of stresses within coating during operational activities reported in (Khan et al., 2017). After acquiring comprehensive historical maintenance data, an efficient neural network technique can be utilised to minimise the error rate between numerically computed predictions and 
events occurred in real time. The combination of historical data with prgnostic calculations will minimise the error rate that will help maintenance professionals to make precise and efficent maintenance decisions.

Table 2. Uniform database for maintenance of metal structures

\begin{tabular}{|c|c|}
\hline Parameter & Description \\
\hline Inspection history & $\begin{array}{l}\text { The inspection process is time-consuming activity especially in } \\
\text { aerospace, museums and automotive industries where a large number of } \\
\text { metal structures are operating. The comparison between the frequency of } \\
\text { inspection in past and degree of delamination can help to manage the } \\
\text { inspection policy accordingly. It can also result in a decrease in the } \\
\text { frequency of inspection and any cost associated with the inspection. }\end{array}$ \\
\hline Coating thickness & $\begin{array}{l}\text { The appropriate selection of coating thickness can result in an increase in } \\
\text { adhesion between the coating and substrate. It can enhance the durability } \\
\text { but it will also impact the cost of coating. }\end{array}$ \\
\hline Interfacial roughness & $\begin{array}{l}\text { The roughness at the interface of substrate affects the adhesion between } \\
\text { coating and substrate. The appropriate value of roughness can result in } \\
\text { increase in adhesion. }\end{array}$ \\
\hline Salinity & $\begin{array}{l}\text { The salinity reacts with water to form an electrochemical cell which } \\
\text { results in corrosion damage and coating failure(Latif et al., 2018a). The } \\
\text { prediction can be made more efficient based on the accumulation of } \\
\text { salinity on structure. }\end{array}$ \\
\hline Stress/Strain & $\begin{array}{l}\text { The change in temperature results in tensile and compressive stresses } \\
\text { within the coating-substrate system (Nazir, Khan, \& Stokes, 2016). The } \\
\text { behaviour of stress/strain throughout the operating period of metal } \\
\text { structure can assist to predict the blisters and cracks propagation in more } \\
\text { accurately in real time environment. }\end{array}$ \\
\hline Meteorological factors & $\begin{array}{l}\text { Different locations on the metal structure may experience different } \\
\text { temperature and humidity level e.g. the Parts inside the metal structure of } \\
\text { large vehicle may experience a different level of temperature and } \\
\text { humidity as compared to Parts outside of the metal structure. }\end{array}$ \\
\hline
\end{tabular}




\begin{tabular}{|c|c|}
\hline Geometrical shape & $\begin{array}{l}\text { According to visual inspection of structures stationed at The Tank } \\
\text { Museum, UK, it was observed that more number of coating failures was } \\
\text { found on curved surfaces as compared to flat surfaces. }\end{array}$ \\
\hline Failure frequency & $\begin{array}{l}\text { It is important to maintain the record of frequency of Patch and Part } \\
\text { failure for specific Parts of metal structures. The history of cost and } \\
\text { frequency of failure will help to better analysis the cost factors for } \\
\text { specific Parts and structures. }\end{array}$ \\
\hline Time-to- maintenance & $\begin{array}{l}\text { The time to complete recoat will differ from strategy to strategy. For } \\
\text { example, the time for complete recoat of the metal structure undergoing } \\
\text { patch recoat maintenance strategy will come later than the structure } \\
\text { undergoing only complete recoat maintenance strategy. }\end{array}$ \\
\hline Type of coating applied & $\begin{array}{l}\text { The multilayered coating is applied to a metal structure having different } \\
\text { characteristics such as corrosion resistant and for decorative purpose. }\end{array}$ \\
\hline Operational activities & $\begin{array}{l}\text { The decay in the useful life of coating of structures operating in a } \\
\text { controlled environment is different from those operating in uncontrolled } \\
\text { environmental conditions. }\end{array}$ \\
\hline $\begin{array}{l}\text { Area recoated (specific } \\
\text { to Part) }\end{array}$ & $\begin{array}{l}\text { The area to be recoated can also be classified by using ASTM D610 } \\
\text { standard which identify the degree of rusting and area to be coated } \\
\text { ("Standard Practice for Evaluating Degree of Rusting on Painted Steel } \\
\text { Surfaces," 2012). }\end{array}$ \\
\hline Cost factors & $\begin{array}{l}\text { The cost factors includes the cost of surface treatment, washing, } \\
\text { preparing equipment for application of coating, labour hours, washing, } \\
\text { drying and other associated activities.. }\end{array}$ \\
\hline Prediction error & $\begin{array}{l}\text { In predicting the maintenance alerts, there is still a huge gap between } \\
\text { real-time scenarios and theoretical calculations. Real-time monitoring } \\
\text { along with neural networks can also be applied to past and theoretical } \\
\text { data to make more accurate and precise predictions. }\end{array}$ \\
\hline
\end{tabular}




\subsection{Cost of recoating maintenance}

The algorithmic framework for cost-effective maintenance decisions can be developed by fusing the techniques of multidisciplinary prognostic modelling with cost estimation methods. The relation to evaluating the annual cost in the field of economics (Tam \& Stiemer, 1996) is given as follows:

$$
\text { Annual cost }=F_{c} \frac{i r}{(1+i r)^{t}-1}
$$

where ' $F^{\prime}{ }_{c}$ is future cost, ' $i r^{\prime}$ is interest rate and exponent ' $t$ ' is annual time. In maintenance, several cost factors are involved which includes the cost of surface preparation, cost of application of coating containing blast abrasives, inspection, maintenance facilities, preparation of coating equipment and containment apparatus. The time ' $t$ ' is the annual time duration of useful coating life. The time ' $t$ ' depends on de-bonding driving force which needs to be forecasted based on properties of individual metal structure and coating materials along with historical maintenance database as described in previous section. In case of Patch recoat, ' $t$ ' is duration when de-bonding driving force remained in safe condition. The coating-substrate system considered for patch recoat when debonding driving force exceeds critical level. According to the requirement of recoating application, the modified relation for annual $\operatorname{cost}^{\prime} F_{c}{ }^{\prime}$ can be given as:

$$
\text { Annual cost }=(\text { Area_Recoat })(\text { Cost_factor })(\text { unit_cost })\left[\frac{i r}{(1+i r)^{t}-1}\right]
$$

In order to find the Total_Area_Recoat factor, the area of an individual part to be recoated is determined. The ASTM D610 which evaluates the amount of rusting on coated steel surfaces can be used to classify the corrosion rating and area required to be coated ("Standard Practice for Evaluating Degree of Rusting on Painted Steel Surfaces," 2012).

$$
\text { Area_Recoat }_{i}=\left[\frac{\text { Area_to_be_coated }(\%)}{100}\right]\left(\text { Surf_area_Part }{ }_{i}\right)
$$

The total area to be recoated can be determined by the summation of individual parts as:

$$
\text { Total_Area_Recoat }=\sum_{i=0}^{n} \text { Area_Recoat } t_{i}
$$

The metal structures are assembled of multiple parts with various geometrical shapes. The individual Part area and the total area of structure can vary from structure to structure. The area of multiple Parts and total area need to be measured according to a specific metal structure. 
The coating maintenance can be divided into three recoating strategies as (Tam \& Stiemer, 1996):

\section{Patch recoat}

$$
\text { Annual cost }=\text { Area }_{\text {Recoat }} *\left(\operatorname{surf}_{\text {prep }}{ }_{\text {cost }}+\text { coating }_{\text {cost }}\right)\left[\frac{i r}{(1+i r)^{t}-1}\right]
$$

\section{Part recoat}

$$
\text { Annual cost }=\left(\text { Area }_{\text {Recoat }} * \operatorname{sur}_{\text {prep }_{\text {cost }}}\right)+\left(\text { area } * \text { coating }_{\text {cost }}\right)\left[\frac{i r}{(1+i r)^{t}-1}\right]
$$

\section{Complete recoat}

$$
\text { Annual cost }=\text { area } *\left(\operatorname{surf}_{\text {prep }_{\text {cost }}}+\text { coating }_{\text {cost }}\right)\left[\frac{i r}{(1+i r)^{t}-1}\right]
$$

The inflation rate provides the rate of variation in the cost of goods and services. The term $(1+i r)^{t}$ can be incorporated in the Equations (13), (14) and (15) as following:

\section{Patch recoat}

$$
\text { Annual cost }=\text { Area }_{\text {Recoat }} *\left(\operatorname{surf}_{\text {prep }}{ }_{\text {cost }}+\text { coating }_{\text {cost }}\right)\left[\frac{i r(1+i r)^{t}}{(1+i r)^{t}-1}\right]
$$

\section{Part recoat}

$$
\text { Annual cost }=\left(\text { Area }_{\text {Recoat }} * \operatorname{surf}_{\text {prep }}{ }_{\text {cost }}\right)+\left(\text { area } * \text { coating }_{\text {cost }}\right)\left[\frac{\operatorname{ir}(1+i r)^{t}}{(1+i r)^{t}-1}\right]
$$

\section{Complete recoat}

$$
\text { Annual cost }=\operatorname{area} *\left(\operatorname{surf}_{\text {prep }} \text { cost }+ \text { coating }_{\text {cost }}\right)\left[\frac{\operatorname{ir}(1+i r)^{t}}{(1+i r)^{t}-1}\right]
$$

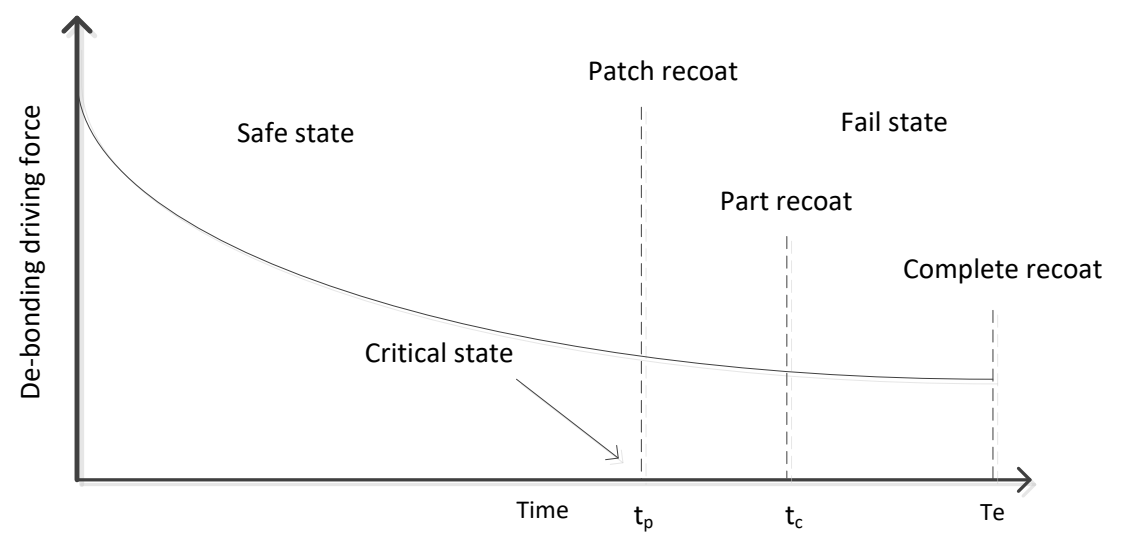

(a) Profile for de-bonding driving force 


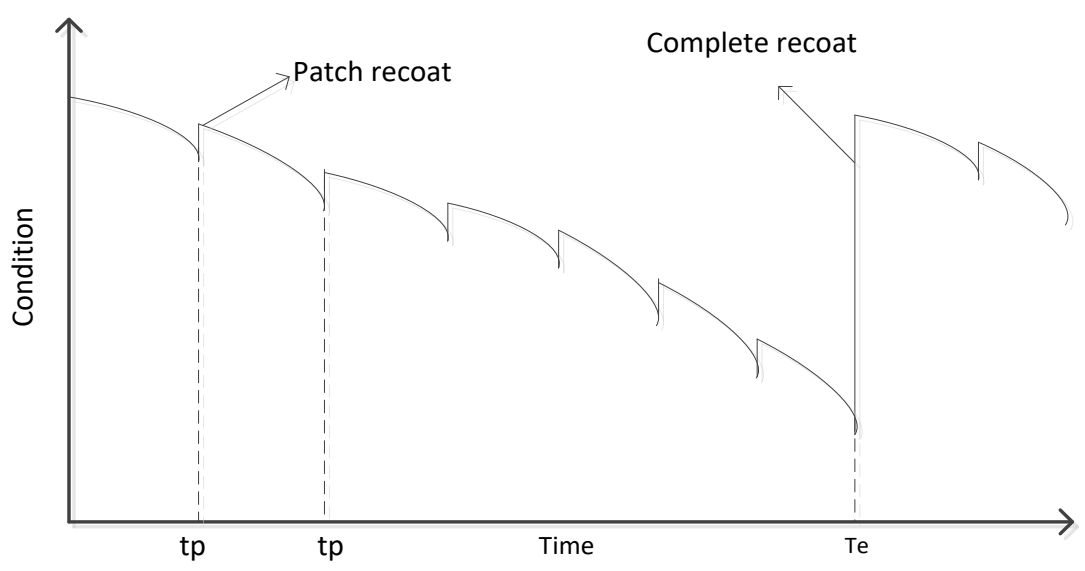

(b) Profile for Patch recoat maintenance strategy

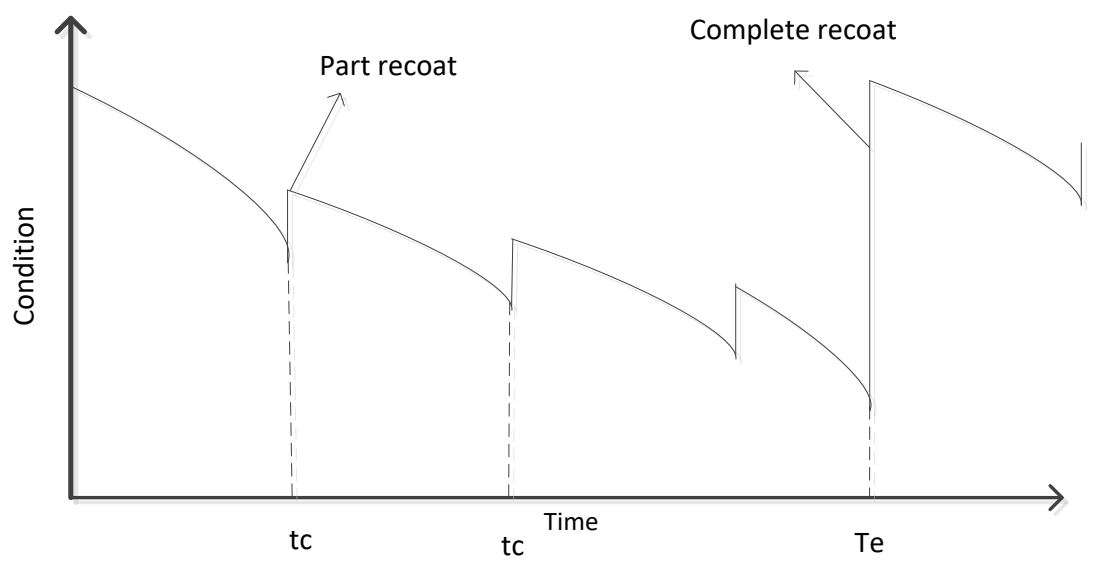

(c) Profile for Part recoat maintenance strategy

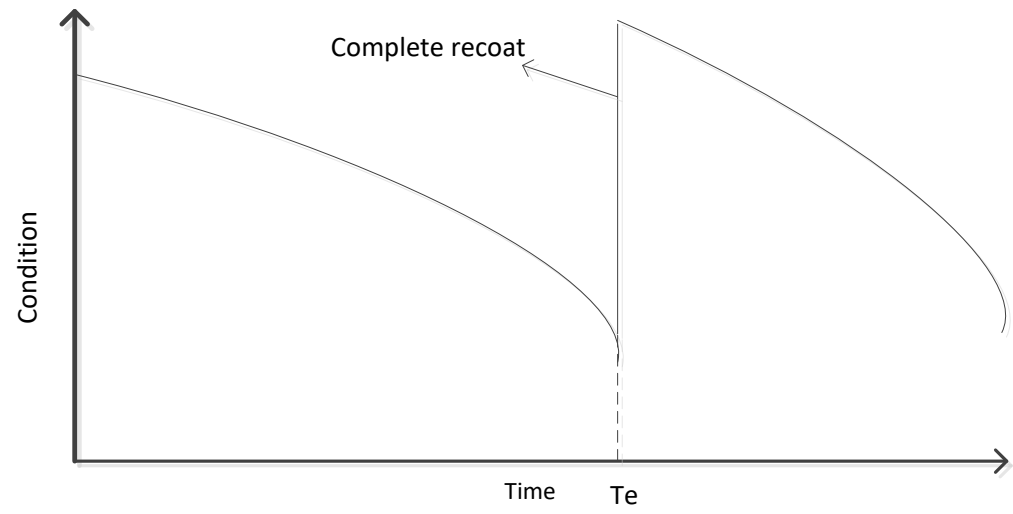

(d) Profile for Complete recoat maintenance strategy

Figure 5. Profiles for de-bonding driving force and maintenance strategies

The maintenance profiles of metal structures associated with maintenance strategies have been shown in the Figures $5 \mathrm{~b}, 5 \mathrm{c}$ and $5 \mathrm{~d}$. In Patch recoat maintenance strategy, only affected area is recoated that could be the formation of blisters, rusting or cracks. The Patch recoat is effective to stop the damage at the earliest stage but more frequent structural health inspection is required than other 
maintenance strategies. The history of inspection and associated degree of deterioration of the coating-substrate system can be used to minimise the inspection frequency in future. The structure may require several patch recoats at a different location of a metal structure with time but it will undergo complete recoat after the appropriate time limit. The cost factors can also vary for patch recoats depending on the location of the structure and geometrical shape. The profile for patch recoats is shown in the Figure 5b. The relation for the total annual cost for patch recoat maintenance strategy can be formalised as following:

$$
\text { Annual cost }_{\text {Patch recoat }}=\sum_{p=0}^{n} A r_{p} *\left(S p_{p}+C_{p}\right)\left[\frac{i r(1+i r)^{t}}{(1+i r)^{t_{n}}-1}\right]+\sum_{e=0}^{n} A_{e} *\left(S p_{e}+C_{e}\right)\left[\frac{i r(1+i r)^{t}}{(1+i r)^{T_{e}}-1}\right]
$$

Once coating failure occurs in the form of blisters or cracking, it will propagate with time leading to part failure. The large metal structures are designed in complex geometrical structures and assembled with numerous metallic parts. The parts at different locations may experience diverse factors for the coating and structure damage. Some Part may require frequent recoat than other Parts. The degree of inspection required to identify Part recoat will be less than as compared to patch recoat and it will usually occur later than patch failure. The area of parts and geometrical shapes may differ from each other so does the cost of area preparation and coating application. The profile associated with Part recoat is shown in the Figure 5c. The metal structure receiving Part recoating strategy will also undergo complete recoat after the appropriate time limit. The relation for the total annual cost for Part recoat maintenance strategy can be formalised as following:

$$
\text { Annual cost }_{\text {Part recoat }}=\sum_{c=0}^{n}\left(A r_{c} * S p_{c}\right)+\left(S p_{c} * C_{c}\right)\left[\frac{i r(1+i r)^{t}}{(1+i r)^{t_{c}}-1}\right]+\sum_{e=0}^{n} A_{e} *\left(S p_{e}+C_{e}\right)\left[\frac{i r(1+i r)^{t}}{(1+i r)^{T_{e}}-1}\right]
$$

In Complete recoat maintenance strategy, the complete structure is recoated once the condition of the metal structure has reached a certain level of deterioration. The frequency of inspection required for complete recoat will be less as compared to other maintenance strategies. The profile for complete recoat is shown in the Figure $5 \mathrm{~d}$. The relation for the total annual cost for complete recoat maintenance strategy can be formalised as follows:

$$
\text { Annual cost }{ }_{\text {Complete recoat }}=\sum_{e=0}^{n} A_{e} *\left(S p_{e}+C_{e}\right)\left[\frac{i r(1+i r)^{t}}{(1+i r)^{T_{e}}-1}\right]
$$

The frequency of inspection can vary depending on the complexity of structure and operating conditions. The cost associated with inspection and the movement of a structure for inspection or for the recoating purpose can be written as follows:

$$
x_{-} \operatorname{Cost}=\sum_{i=0}^{n} \mathrm{i}_{-} \operatorname{Cost}_{i}\left[\frac{i r(1+i r)^{t}}{(1+i r)^{t_{i}}-1}\right]+\sum_{m=0}^{n} m_{-} \operatorname{Cost}_{m}\left[\frac{i r(1+i r)^{t}}{(1+i r)^{t_{m^{-}}}-1}\right]
$$


where $x_{-}$Cost is representing the accumulative cost of number of inspections carried out at different time intervals and any cost of moving the structure/military vehicle for inspection or recoating purpose. Above relation can be incorporated in Equations (19), (20) and (21) resulting in relations to find annual cost based on frequency of inspections and cost that could include the movement of an military vehicle for recoating or inspection purpose as follows:

$$
\begin{aligned}
\text { Annual cost }_{\text {Patch recoat }} & =\sum_{p=0}^{n} A r_{p} *\left(S p_{p}+C_{p}\right)\left[\frac{i r(1+i r)^{t}}{(1+i r)^{t_{n}-}-1}\right] \\
& +\sum_{e=0}^{n} A_{e} *\left(S p_{e}+C_{e}\right)\left[\frac{i r(1+i r)^{t}}{(1+i r)^{T_{e}}-1}\right]+\sum_{i=0}^{n} \mathrm{i}_{-} \operatorname{Cost}_{i}\left[\frac{i r(1+i r)^{t}}{(1+i r)^{t_{i}-}-1}\right]+\sum_{m=0}^{n} m_{-} \operatorname{Cost}_{m}\left[\frac{i r(1+i r)^{t}}{(1+i r)^{t_{m^{-}}-1}}\right] \\
\text { Annual cost }_{\text {Part recoat }}= & \sum_{c=0}^{n}\left(A r_{c} * S p_{c}\right)+\left(S p_{c} * C_{c}\right)\left[\frac{i r(1+i r)^{t}}{(1+i r)^{t_{c}}-1}\right] \\
& +\sum_{e=0}^{n} A_{e} *\left(S p_{e}+C_{e}\right)\left[\frac{i r(1+i r)^{t}}{(1+i r)^{T_{e}}-1}\right]+\sum_{i=0}^{n} \mathrm{i}_{i} \operatorname{Cost}_{i}\left[\frac{i r(1+i r)^{t}}{(1+i r)^{t_{i}-}-1}\right]+\sum_{m=0}^{n} m_{-} \operatorname{Cost}_{m}\left[\frac{i r(1+i r)^{t}}{(1+i r)^{t_{m}}-1}\right]
\end{aligned}
$$

Annual cost Complete recoat $_{\text {in }}$

$$
=\sum_{e=0}^{n} A_{e} *\left(S p_{e}+C_{e}\right)\left[\frac{i r(1+i r)^{t}}{(1+i r)^{T_{e}}-1}\right]+\sum_{i=0}^{n} \mathrm{i}_{-} \operatorname{Cost}_{i}\left[\frac{i r(1+i r)^{t}}{(1+i r)^{t_{i}-}-1}\right]+\sum_{m=0}^{n} m_{-} \operatorname{Cost}_{m}\left[\frac{i r(1+i r)^{t}}{(1+i r)^{t_{m}}-1}\right]
$$

\section{Algorithm implementation}

The algorithm for maintenance strategy evaluation has been simulated and elaborated comprehensively through flow diagram as shown in the Figure 6. The recoating maintenance strategy algorithm contains two primary sections. One section performs prognostic modelling while other computes the annual cost of recoating maintenance. Various scenarios can be simulated for evaluation considering properties of coating materials, different geometrical shapes of metal structures, meteorological parameters etc... In current simulation and analysis, two propositions have been considered.

Proposition 1: The experimental findings show that the thickness of the coating is proportional to the adhesion of the coating and substrate system. As the thickness of the coating increases the development of blister failure will take more time. The development of blister is taken as patch failure and the algorithm is simulated to evaluate the financial impact of the thickness of the coating on annual cost of patch undergoes Patch recoating maintenance strategy.

Proposition 2: In this scenario, two different recoating maintenance strategies are compared with each other. The impact of Patch recoating and Part recoating strategy on the annual cost of maintenance is evaluated. In Patch recoating the only affected area/patch needs to be treated while in Part recoating requires maintenance treatment of whole component/part of the structure. In order to create all possible conditions, the area of patch to be recoated is taken constant and numbers of patches per year are increased for next ten years. These patches are then compared with various area 
of parts such as $2 \mathrm{x}$ (twice the area of patch area), $3 \mathrm{x}$ (thrice the area of patch area) etc...The prognostic model to estimate the de-bonding driving force for blistering failure has already been validated through experimental observations mentioned in publications by NCEM research group (Latif et al., 2018b; Nazir, Khan, Saeed, et al., 2015; Nazir, Khan, et al., 2015c; Nazir, Khan, \& Stokes, 2016).

For simulation analysis, the properties of red oxide primer coating and structural steel S275 as substrate are considered as they have been investigated in previous experimental analysis. The red oxide primer coating has Young's modulus ' $\mathrm{E}$ ' $=6.14 \mathrm{GPa}$ and the coefficient of thermal expansion ' $\alpha^{\prime}=21.6 \times 10^{-6} / K$. While, the structural steel S275 has Young's modulus 'E' $=210 \mathrm{GPa}$ and the coefficient of thermal expansion ' $\alpha_{c}{ }^{\prime}=12 \times 10^{-6} / K$ (Latif et al., 2018b). In order to implement the prognostic model for de-bonding driving force, the parameters are converted into dimensionless form.

Initial boundary conditions:

$$
\begin{array}{cl}
c_{k_{c_{i}}}(x)=c_{k_{s}}=0 & \text { for time } t=0 \\
c_{k_{c_{i}}}(h)=c_{k_{0}} & \text { fortime } t>0
\end{array}
$$

The parameters are converted into a dimensionless form for numerical simulation as following:

$$
\begin{gathered}
\widetilde{c_{k_{c_{l}}}}=c_{k_{c_{i}}} / c_{k_{0}} \\
\breve{E}=\frac{2}{3} \sum_{i=1}^{n} \frac{E_{i}}{\left(1-v_{i}{ }^{2}\right) E_{s}} \\
\widetilde{D_{k}}=D_{k_{c_{i}}} / D_{k_{s}} \\
\tilde{A}=\left(\frac{E_{c_{i}} V_{p_{c_{c_{i}}}}^{2}}{R T}\right) c_{k_{0}} \\
\frac{1}{\check{\rho}_{d_{i}}}=\frac{1}{\rho_{d_{i}} c_{k_{0}} V_{p_{k_{0}}}}=6 \sum_{i=1}^{n} \frac{E_{i} t_{i}\left(c_{k_{i}}^{\prime} \overline{V_{k_{k}}}-c_{k_{s}}^{\prime} \overline{V_{p_{s}}}\right)}{E_{S} s^{2} c_{k_{0}} V_{p_{k_{0}}}} \\
\frac{1}{\check{\rho}_{r_{i}}}=\frac{1}{\rho_{r_{i}} \alpha_{k_{0}} \Delta T_{k_{0}}}=6 \sum_{i=1}^{n} \frac{E_{i} t_{i}\left(\alpha_{i}-\alpha_{s}\right) \Delta T}{E_{S} s^{2} \alpha_{k_{0}} \Delta T_{k_{0}}}
\end{gathered}
$$




$$
\check{x}=\left(\left(x_{i+1}-t_{p}\right)^{3}-\left(x_{i}-t_{p}\right)^{3}\right) /\left(s+T_{t h}\right)
$$

The dimensionless form of parameters in Equations (3) and (6) gives following relation for debonding driving force:

$$
\begin{gathered}
\widetilde{F}=\frac{(1 / \tilde{E}) \widetilde{M}(1 / \tilde{x})}{1+\tan \left((1-\widetilde{\boldsymbol{B}}) \frac{1}{-\tan \omega}\right)^{2}}\left[1+\frac{1}{4}\left(\sqrt{n-1}^{2}\right)\right] \\
\tilde{F}_{c r}=\frac{(1 / \tilde{E}) \widetilde{M}(1 / \tilde{x})}{1+\tan \left((1-\widetilde{\boldsymbol{B}}) \frac{1}{-\tan \omega}\right)^{2}}
\end{gathered}
$$

The relation for de-bonding driving is computed through numerical simulation using timeiterative Runge-kutta method. Following steps are involved in solving prognostic modelling section.

a. The algorithm takes input parameters which include various material, chemical, mechanical, and cost parameters.

b. The critical de-bonding driving force ' $\tilde{F}_{c r}$ ' is computed using Equation (28).

c. As the de-bonding driving force is function of resultant stress, the algorithm updates ' $\sigma_{T}$ ' using time iterative method to solve ' $\widetilde{\widetilde{F}}^{\prime}$ in Equation (27).

d. The algorithm then compares the de-bonding driving force to find the critical, safe and fail condition according to Table 1.

e. The algorithm repeats the ' $c$ ' and ' $d$ ' unless de-bonding driving force exceeds the critical debonding driving force.

The second section contains computation of annual cost for various recoating maintenance strategies. For proposition 1, the algorithm computed the annual cost for Patch recoat with various coating thickness. In preposition 2, the algorithm is computing annual cost for patch recoat and Part recoat strategy including one complete recoat in both cases. The algorithm calculates the annual cost for next e.g.. 10 years duration starting from 1 Patch failure per year and similarly calculates the cost for next 10 years by incrementing a number of patch failure per year (from 1 to 10 patches/year).

Once the cost for the patch failure strategy is computed algorithm moves to Part recoat strategy to calculate the annual cost of maintenance by increasing the area of complete Part failure requires recoating. The algorithm calculates the coating cost for next e.g... 10 years considering the area of Part failure is ' $2 x$ ' times than area of patch failure. Similarly, it continues calculating the annual cost by increasing area of Part failure till '10x' which means the area of the Part to be recoated is 10 times greater than the area of patch failure. 


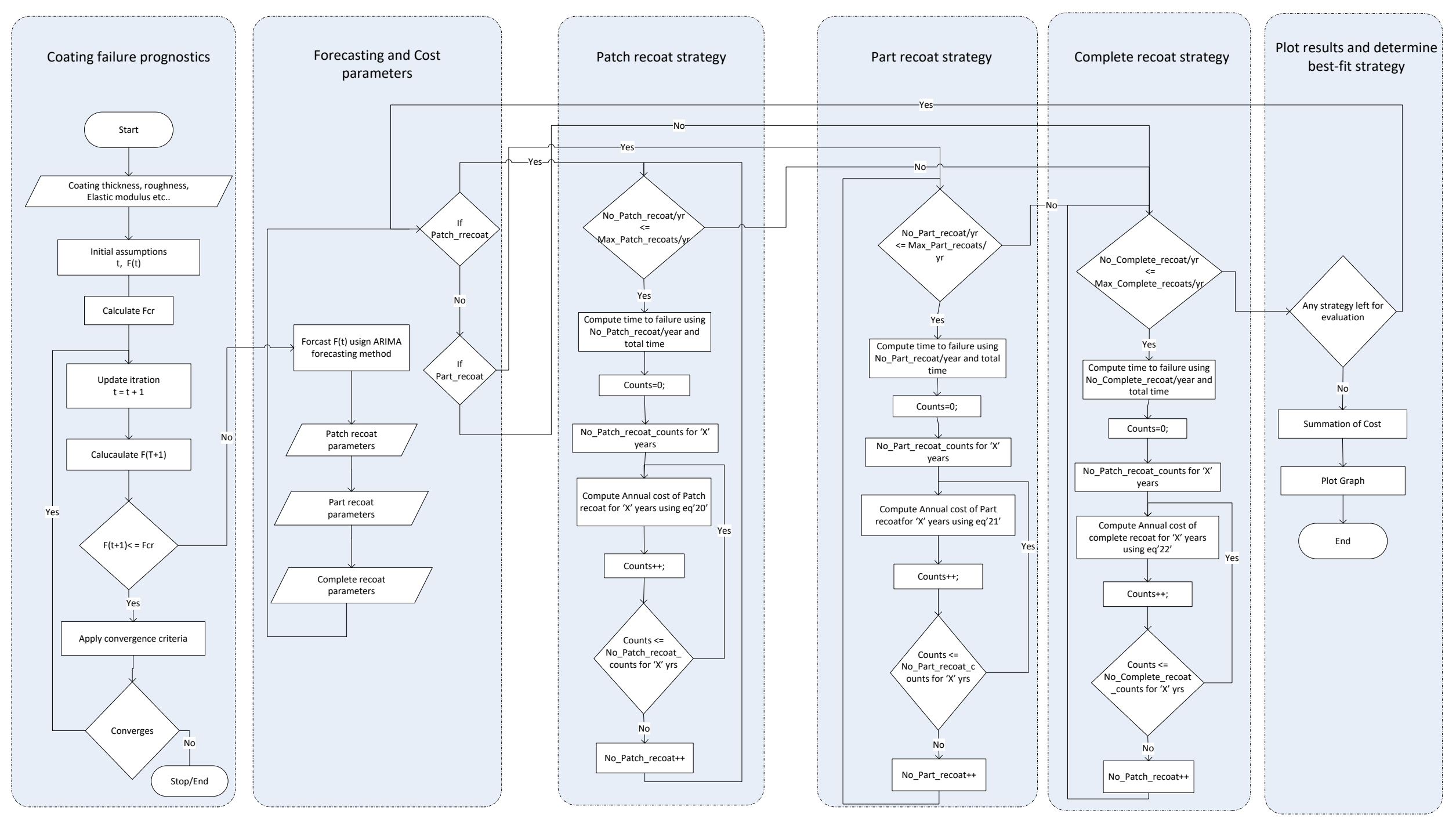

Figure 6. Recoating Maintenance Strategy Evaluation Simulation 


\section{Results and discussion}

Proposition 1: The simulation results for de-bonding driving force ' $\widetilde{\widetilde{F}}$ ' for various relative coating thickness $\left(T_{t h} / \mathrm{s}\right)$ as a function of de-bonding index $(\cap)$ is shown in Fig. 7. As the relative coating thickness increases, the coating and substrate system has high critical de-bonding driving force level $\left(f c r_{n}\right)$. At relative coating thickness $=0.1$, the level of critical de-bonding driving force ' $f c r_{1}^{\prime}$ is lower as compare to critical de-bonding driving force ' $f c r_{2}^{\prime}$. Similarly, the ' $f c r_{2}^{\prime}$ with relative coating thickness $=0.2$ is lower than the critical de-bonding driving force ' $f c r_{3}^{\prime}$ with relative coating thickness $=0.3$. When the value of debonding index $(\Omega)$ is less than 1 , the system is considered in safe condition and no blister failure has occurred which is referenced as patch failure in current simulation.

When the critical de-bonding driving force exceeds the critical level then patch failure has occurred and patch recoating maintenance is required. The increase in thickness raises the level of adhesion so does critical level for coating and substrate system. The high level of critical de-bonding driving force means that the coating and substrate system will take more time to reach patch failure called as fail condition. The increase in thickness of coating results in less number of patch failures resulting in reduction in recoating maintenance. The comparison of annual cost of different relative coating thickness is shown in Figure 8. Although, increasing the thickness of coating also increases the amount of coating to be applied so does the cost but the reduction in Patch recoating maintenance activities resulted in lower annual cost for high relative coating thickness system. According to current simulations, it can be concluded that the appropriate coating thickness for specific structure can be selected to optimise the cost of recoating maintenance.

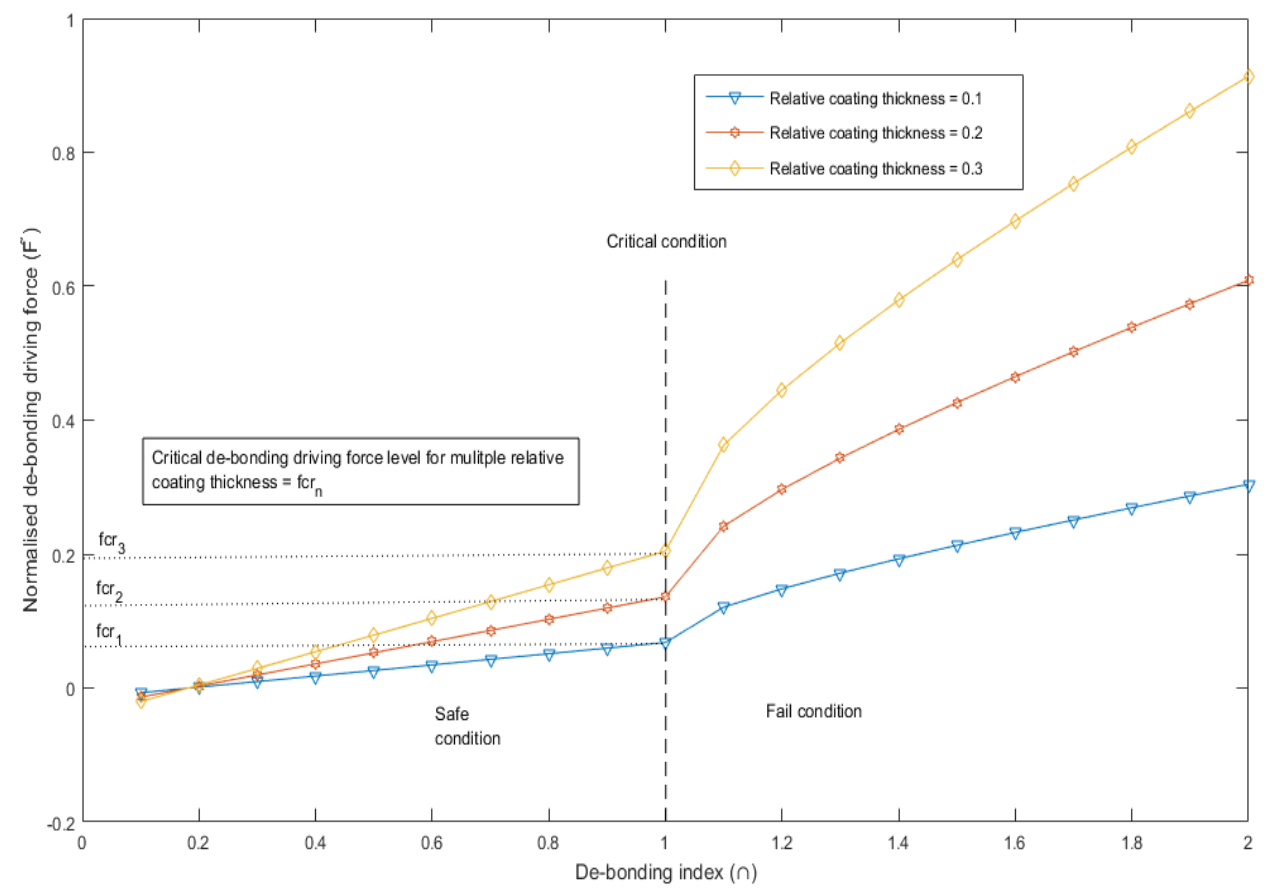

Figure 7. The behaviour of de-bonding driving force as function of de-bonding index 
Proposition 2: The simulation results are shown in the Figure 9 explaining the multiple scenarios to make a comparison between Patch recoat strategy and Part recoat strategy. Each value on the graph is presenting the annual cost for 10 years period of time. For simulation, the unit costs of coating and surface preparations for both strategies are considered equal and at least one complete recoat per year is considered for both strategies. The cost for complete recoat is also kept the same in both maintenance strategies. The objective of the current analysis is an evaluation of the best maintenance strategy among Patch recoat and Part recoat for metal structures experiencing patch failures leading to Part failures. For Patch recoat calculations, the algorithm starts with computing the annual cost for next 10 years considering one patch recoat and one complete recoat.

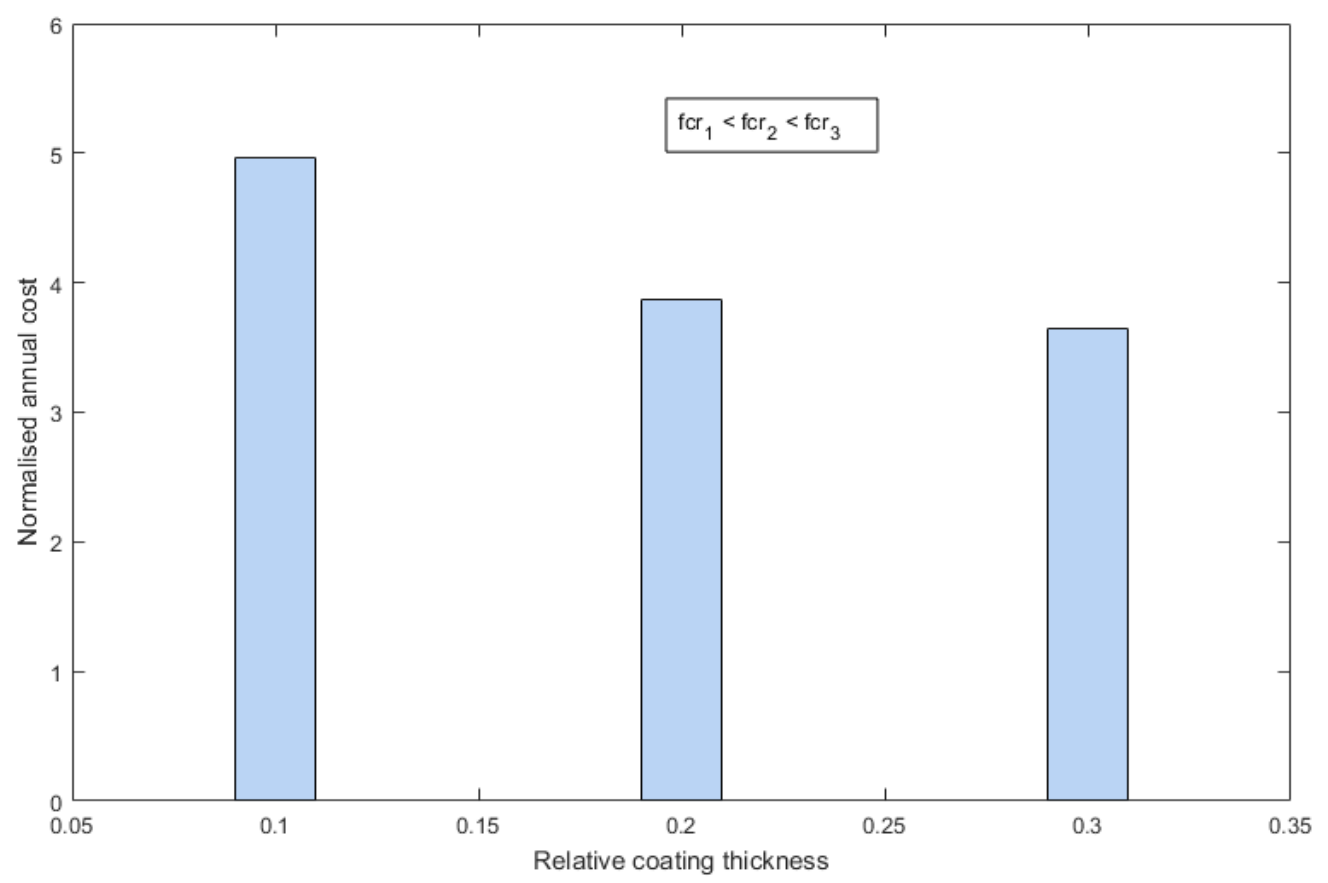

Figure 8. Normalised annual cost as a function of relative coating thickness

Similarly in the next iteration algorithm considers 2 patches recoat per year and computes annual cost for next 10 years. The cost is converted into normalised value by taking ratio with a maximum value of cost. The annual cost of patch recoat is increasing linearly as the number of patches per year increases and its maximum for 10 patches per year as shown in Figure 7. For the Part recoat strategy, the annual cost is computed for variable area of Parts which requires complete Part recoating. The Part recoat area ' $2 \mathrm{x}$ ' means the area of a Part selected for complete Part recoat is two times greater than the area of patch failure. Similarly, the cost of Part recoat area '10x' means the area of a Part selected for complete Part recoat is 10 times greater than the area of patch failure.

The algorithm has suggested different best fit maintenance strategies depending on the area of Part failure as compared to patch failure. The point A is marked on the graph to explain the scenario where the cost of both maintenance strategies crossing each other. The point A describes that the Patch recoat strategy is resulting in low cost when a number of patch recoats are less than 4 per year 
and area of the Part is 5 times greater than the area of Patch failure. The Part recoat strategy is resulting in low cost when patch recoat exceeds 4 per year and Part area is 5 times greater than the area of patch failure requires recoating.

The conclusion from point A can be considered as, if the metal structure is experiencing less than 4 patch recoat and its Part area is 5 times greater than patch failure than Patch recoat maintenance strategy is cost-effective maintenance strategy for corresponding metal structure. However, if the same metal structure is experiencing more than 4 patches failure per year than Part recoat strategy is more cost effective as compare to Patch recoat strategy. The simulation result shows several crossing for different area of Part and number of patch failures. The conclusion can be made for the specific metal structure based on the frequency of its patch failures per year and area of Parts.

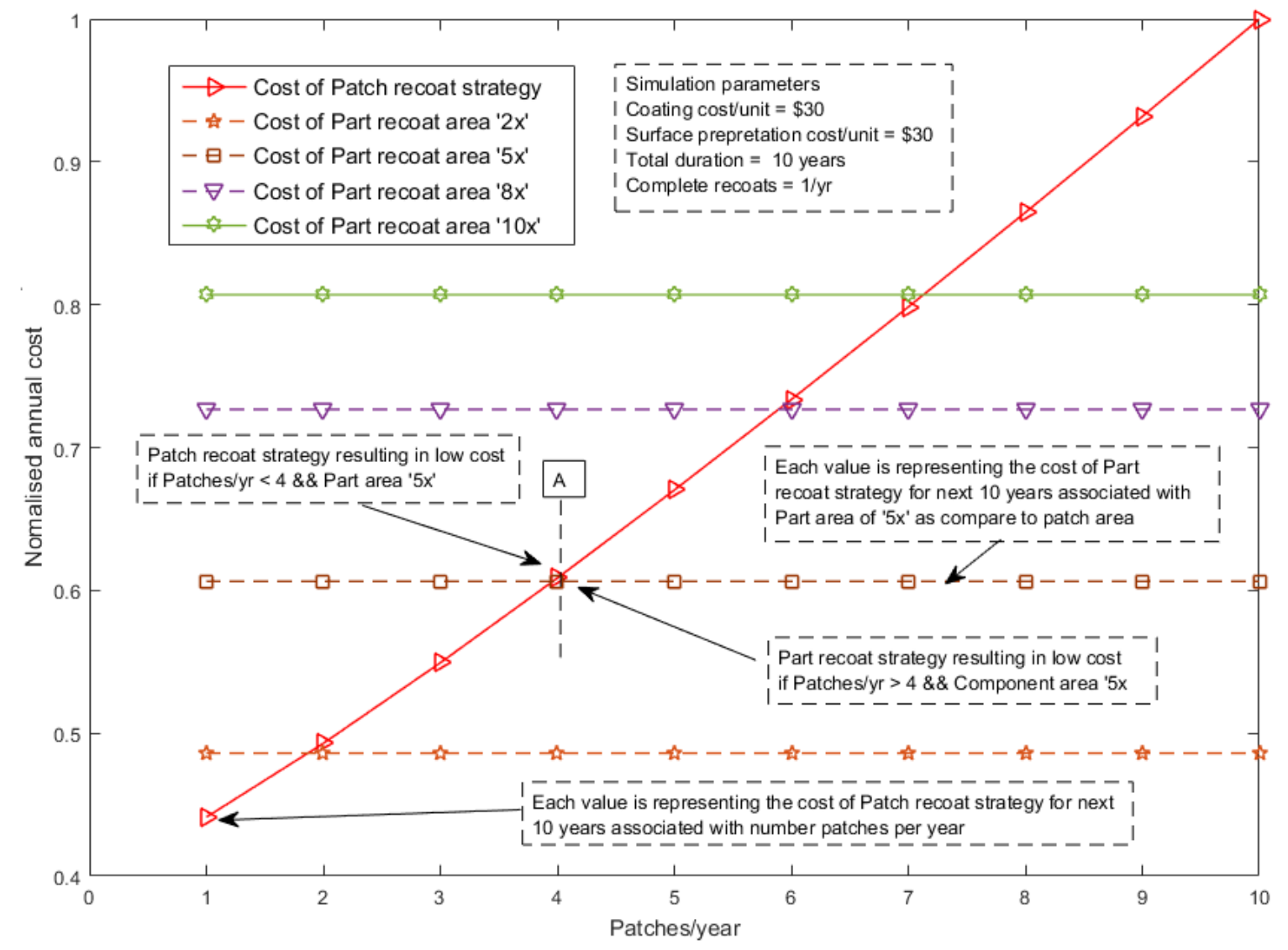

Figure 9. Simulation results for recoating maintenance strategy for metal structures

\section{Conclusion}

The current work presents very compressive and realistic approach to evaluate optimal recoating maintenance strategy for complex metal structures. The maintenance cost for structures can be evaluated by applying numerous scenarios to the proposed algorithm. The major limitations in the in implementation of proposed algorithm are the benchmark for part failure for specific metal structure, historical maintenance data based on model parameters and real time monitoring data of operating locations. 
The future work involves development of prognostic models leading to part failure and the collection of the maintenance parameters in real-time to utilise the proposed algorithm more effectively. The NCEM research group is also developing real-time condition monitoring system to acquire various parameters which are required for maintenance model. The fusion of real-time monitoring system, maintenance history database and prognostic models leading to part and complete failure will make the proposed system algorithm more efficient. The collection and management of uniform maintenance history in the form of a database of the individual structure is one of the major complications to make the maintenance algorithm efficient for real-time scenarios. It is recommended to professionals and researchers to develop a mechanism of maintaining a uniform database of maintenance history associated with specific structures which incorporates all the possible parameters investigated in modern research findings.

\section{Acknowledgements}

This research is jointly funded by Defence Science and Technology Laboratory (DSTL), Ministry of Defence (MoD) UK and Bournemouth University. The authors acknowledge their financial support and in-kind contributions.

\section{Disclosure statement}

There is no conflict of interest regarding this article.

\section{References}

Bressers, J., Peteves, S., \& Steen, M. (2000). Coatings for hot section gas turbine componentsEuropean Structural Integrity Society (Vol. 26, pp. 115-134): Elsevier. doi: 10.1016/S1566-1369(00)80045-X

Cavallo, T., Pagani, A., Zappino, E., \& Carrera, E. (2018). Effect of Localized Damages on the Free Vibration Analysis of Civil Structures by Component-Wise Approach. Journal of Structural Engineering, 144(8). doi: 10.1061/(ASCE)ST.1943-541X.0002128

Chuang, T.-J., Nguyen, T., \& Lee, S. (1999). Micro-mechanic model for cathodic blister growth in painted steel. Journal of Coatings Technology, 71(895), 75-85. doi: 10.1007/BF02697925

Chuang, T., Nguyen, T., \& Li, S. (1997). A non-osmotic blister growth model in coating systems. Paper presented at the Damage and failure of interfaces. 1st International Conference. Proceedings.

Faulhaber, S., Mercer, C., Moon, M.-W., Hutchinson, J., \& Evans, A. (2006). Buckling delamination in compressed multilayers on curved substrates with accompanying ridge cracks. Journal of the Mechanics and Physics of Solids, 54(5), 1004-1028. doi: 10.1016/j.jmps.2005.11.005

Galindo, R. E., Van Veen, A., Evans, J., Schut, H., \& de Hosson, J. T. M. (2005). A modified blister test to study the adhesion of thin coatings based on local helium ion implantation. Thin Solid Films, 471(1-2), 170-176. doi: 10.1016/j.tsf.2004.06.129

Gong, C., \& Zhou, W. (2018). Multi-objective maintenance strategy for in-service corroding pipelines using genetic algorithms. Structure and Infrastructure Engineering, 14(11), 1561-1571. doi: $10.1080 / 15732479.2018 .1459744$

Hertzberg, E. (2016). Estimated Impact of Corrosion on Cost and Availability of DoD Weapon Systems: FY2016: Report SAL4IT2.

Herzberg, E. F., Ambrogio, E. D., Barker, C. L., Harleston, E. F., Haver, W. M., O’Meara, N. T., . . . Tran, J. C. (2006). The Annual Cost of Corrosion for Army Ground Vehicles and Navy Ships. LMI Report SKT50T1. 
Hsueh, C.-H. (2002). Modeling of elastic deformation of multilayers due to residual stresses and external bending. Journal of applied physics, 91(12), 9652-9656. doi: 10.1063/1.1478137

Hutchinson, J. W. (1996). Stresses and failure modes in thin films and multilayers. Notes for a Dcamm Course. Technical University of Denmark, Lyngby, 1-45.

Hutchinson, J. W., \& Suo, Z. (1991). Mixed mode cracking in layered materials Advances in applied mechanics (Vol. 29, pp. 63-191): Elsevier.

Irwin, G. R. (1957). Analysis of stresses and strains near the end of a crack traversing a plate. Journal of Applied Mechanics, 24, 351-369.

Kappes, M., Frankel, G., \& Sridhar, N. (2010). Adhesion and adhesion degradation of a pressure sensitive tape on carbon steel. Progress in Organic Coatings, 69(1), 57-62. doi: 10.1016/j.porgcoat.2010.05.005

Khan, Z. A., Latif, J., Hammad Nazir, A. S., \& Stokes, K. (2018). Predictive and prognostic modelling and simulation of coatings subject to corrosion and mechanical failures. Materials Characterisation, 6(3), 487-498. doi: 10.2495/CMEM-V6-N3-1-13

Khan, Z. A., Latif, J., Nazir, M. H., Stokes, K., \& Plummer, J. (2017). Sensor based corrosion condition monitoring of coating substrate system informed by fracture mechanics, electrochemistry and heat transfer concepts. Paper presented at the Department of Defense Allied Nations Technical Corrosion Conference, Birmingham, AL, USA.

Koch, G., Varney, J., Thompson, N., Moghissi, O., Gould, M., \& Payer, J. (2016). NACE International Impact. In N. I. Gretchen Jacobson, Houston, Texas, USA (Ed.).

Latif, J., Khan, Z. A., Nazir, M. H., Stokes, K., \& Plummer, J. (2018a). Condition monitoring and predictive modelling of coating delamination applied to remote stationary and mobile assets. Structural Health Monitoring. doi: 10.1177/1475921718773524

Latif, J., Khan, Z. A., Nazir, M. H., Stokes, K., \& Plummer, J. (2018b). Life assessment prognostic modelling for multi-layered coating systems using a multidisciplinary approach. Materials Science and Technology, 34(6), 664-678. doi: 10.1080/02670836.2017.1410358

Lim, C., Yan, B., Yin, L., \& Zhu, L. (2012). Simulation of diffusion-induced stress using reconstructed electrodes particle structures generated by micro/nano-CT. Electrochimica Acta, 75, 279-287. doi: 10.1016/j.electacta.2012.04.120

Nazir, M., Khan, Z., \& Stokes, K. (2015a). Modelling of metal-coating delamination incorporating variable environmental parameters. Journal of Adhesion Science and Technology, 29(5), 392423. doi: 10.1080/01694243.2014.990200

Nazir, M., \& Khan, Z. A. (2017). A review of theoretical analysis techniques for cracking and corrosive degradation of film-substrate systems. Engineering Failure Analysis, 72, 80-113. doi: 10.1016/j.engfailanal.2016.11.010

Nazir, M., Khan, Z. A., Saeed, A., \& Stokes, K. (2015). Modeling the effect of residual and diffusioninduced stresses on corrosion at the interface of coating and substrate. Corrosion, 72(4), 500517. doi: $10.5006 / 1804$

Nazir, M., Khan, Z. A., Saeed, A., \& Stokes, K. (2016a). A model for cathodic blister growth in coating degradation using mesomechanics approach. Materials and Corrosion, 67(5), 495503. doi: $10.1002 / \mathrm{maco} .201508562$

Nazir, M., Khan, Z. A., Saeed, A., \& Stokes, K. (2016b). A predictive model for life assessment of automotive exhaust mufflers subject to internal corrosion failure due to exhaust gas condensation. Engineering Failure Analysis, 63, 43-60. doi: 10.1016/j.engfailanal.2016.02.014

Nazir, M., Khan, Z. A., \& Stokes, K. (2015b). A holistic mathematical modelling and simulation for cathodic delamination mechanism-a novel and an efficient approach. Journal of Adhesion Science and Technology, 29(22), 2475-2513. doi: 10.1080/01694243.2015.1071023

Nazir, M., Khan, Z. A., \& Stokes, K. (2015c). Optimisation of interface roughness and coating thickness to maximise coating-substrate adhesion-a failure prediction and reliability assessment modelling. Journal of Adhesion Science and Technology, 29(14), 1415-1445. doi: 10.1080/01694243.2015.1026870

Nazir, M., Khan, Z. A., \& Stokes, K. (2015d). A unified mathematical modelling and simulation for cathodic blistering mechanism incorporating diffusion and fracture mechanics concepts. 
Journal of Adhesion Science and Technology, 29(12), 1200-1228. doi: 10.1080/01694243.2015.1022496

Nazir, M., Khan, Z. A., \& Stokes, K. (2016). Analysing the coupled effects of compressive and diffusion induced stresses on the nucleation and propagation of circular coating blisters in the presence of micro-cracks. Engineering Failure Analysis, 70, 1-15. doi: 10.1016/j.engfailanal.2016.07.003

Nazir, M., Saeed, A., \& Khan, Z. A. (2018). Electrochemical corrosion failure analysis of large complex engineering structures by using micro-LPR sensors. Sensors and Actuators B: Chemical, 268, 232-244. doi: 10.1016/j.snb.2018.02.191

Nazir, M. H., \& Khan, Z. (2015). Maximising the interfacial toughness of thin coatings and substrate through optimisation of defined parameters. International Journal of Computational Methods and Experimental Measurements, 3(4), 316-328. doi: 10.2495/CMEM-V3-N4-316-328

Nazir, M. H., Khan, Z. A., \& Saeed, A. (2018). A Novel Non-Destructive Sensing Technology for On-Site Corrosion Failure Evaluation of Coatings. IEEE Access, 6, 1042-1054. doi: 10.1109/ACCESS.2017.2777532

Nazir, M. H., Saeed, A., \& Khan, Z. (2017). A comprehensive predictive corrosion model incorporating varying environmental gas pollutants applied to wider steel applications. Materials Chemistry and Physics, 193, 19-34. doi: 10.1016/j.matchemphys.2017.01.081

Nielsen, J. S., \& Sørensen, J. D. (2018). Computational framework for risk-based planning of inspections, maintenance and condition monitoring using discrete Bayesian networks. Structure and Infrastructure Engineering, 14(8), 1082-1094. doi: $10.1080 / 15732479.2017 .1387155$

Prawoto, Y. (2013). Unified model for blister growth in coating degradation using weight function and diffusion concepts. Materials and Corrosion, 64(9), 794-800. doi: $10.1002 / \mathrm{maco} .201106404$

Prawoto, Y., \& Dillon, B. (2012). Failure analysis and life assessment of coating: the use of mixed mode stress intensity factors in coating and other surface engineering life assessment. Journal of failure analysis and prevention, 12(2), 190-197. doi: 10.1007/s11668-011-9525-1

Saeed, A., Khan, Z. A., Nazir, H., Hadfield, M., \& Smith, R. (2017). Research impact of conserving large military vehicles through a sustainable methodology. International Journal of Heritage Architecture, 1(2), 267-274. doi: 10.2495/HA-V1-N2-267-274

Saeed, A., Khan, Z. A., \& Nazir, M. H. (2015). An optimised approach of protecting and sustaining large vehicle system. Sustainability, 7(12), 16451-16464. doi: 10.3390/su71215825

Saeed, A., Khan, Z. A., \& Nazir, M. H. (2016). Time dependent surface corrosion analysis and modelling of automotive steel under a simplistic model of variations in environmental parameters. Materials Chemistry and Physics, 178, 65-73. doi: 10.1016/j.matchemphys.2016.04.068

Si, X.-S., Wang, W., Hu, C.-H., \& Zhou, D.-H. (2011). Remaining useful life estimation-a review on the statistical data driven approaches. European journal of operational research, 213(1), 114. doi: 10.1016/j.ejor.2010.11.018

Standard Practice for Evaluating Degree of Rusting on Painted Steel Surfaces. (2012). from https://www.astm.org/Standards/D610.htm

Tam, C., \& Stiemer, S. (1996). Development of bridge corrosion cost model for coating maintenance. Journal of Performance of Constructed Facilities, 10(2), 47-56. doi: 10.1061/(ASCE)08873828(1996)10:2(47)

Totten, G. E. (2002). Handbook of residual stress and deformation of steel: ASM international.

Walker, K. (1970). The effect of stress ratio during crack propagation and fatigue for 2024-T3 and 7075-T6 aluminum Effects of environment and complex load history on fatigue life: ASTM International.

Wan, K.-t., \& Liao, K. (1999). Measuring mechanical properties of thin flexible films by a shaftloaded blister test. Thin Solid Films, 352(1-2), 167-172. doi: 10.1016/S0040-6090(99)003557

Xie, Y., \& Zhang, J. (2018). Design and Optimization of Seismic Isolation and Damping Devices for Highway Bridges Based on Probabilistic Repair Cost Ratio. Journal of Structural Engineering, 144(8), 04018125. doi: 10.1061/(ASCE)ST.1943-541X.0002139 
Yang, S., Xi, X., Li, K., \& Li, C.-Q. (2018). Numerical Modeling of Nonuniform Corrosion-Induced Concrete Crack Width. Journal of Structural Engineering, 144(8), 04018120. doi: 10.1061/(ASCE)ST.1943-541X.0002108

Ye, Z. S., \& Xie, M. (2015). Stochastic modelling and analysis of degradation for highly reliable products. Applied Stochastic Models in Business and Industry, 31(1), 16-32. doi: 10.1002/asmb.2063

Zhang, X., Shyy, W., \& Sastry, A. M. (2007). Numerical simulation of intercalation-induced stress in Li-ion battery electrode particles. Journal of the electrochemical society, 154(10), A910A916. doi: 10.1149/1.2759840 